\title{
Controversies about sugars: results from systematic reviews and meta-analyses on obesity, cardiometabolic disease and diabetes
}

\author{
Tauseef A. Khan ${ }^{1,2} \cdot$ John L. Sievenpiper ${ }^{1,2,3,4}$
}

Received: 13 April 2016 / Accepted: 7 November 2016 / Published online: 30 November 2016

(C) The Author(s) 2016. This article is published with open access at Springerlink.com

\begin{abstract}
Fructose-containing sugars are a focus of attention as a public health target for their putative role in obesity and cardiometabolic disease including diabetes. The fructose moiety is singled out to be the primary driver for the harms of sugars due to its unique endocrine signal and pathophysiological role. However, this is only supported by ecological studies, animal models of overfeeding and select human intervention studies with supraphysiological doses or lack of control for energy. The highest level of evidence from systematic reviews and meta-analyses of controlled trials has not shown that fructose-containing sugars behave any differently from other forms of digestible carbohydrates. Fructosecontaining sugars can only lead to weight gain and other unintended harms on cardiometabolic risk factors insofar as the excess calories they provide. Prospective cohort studies, which provide the strongest observational evidence, have shown an association between fructose-containing sugars
\end{abstract}

This article belongs to a supplement sponsored by Rippe Health.

This paper was previously presented by JLS in the session 'Controversies about sugar consumption' at the 12th European Nutrition Conference FENS 2015, Berlin, Germany, 21 October 2015.

John L. Sievenpiper

john.sievenpiper@utoronto.ca

1 Department of Nutritional Sciences, Faculty of Medicine, University of Toronto, Toronto, ON, Canada

2 Toronto 3D Knowledge Synthesis and Clinical Trials Unit, Clinical Nutrition and Risk Factor Modification Centre, St. Michael's Hospital, Toronto, ON, Canada

3 Division of Endocrinology and Metabolism, St. Michael's Hospital, Toronto, ON, Canada

4 Li Ka Shing Knowledge Institute, St. Michael's Hospital, Toronto, ON, Canada and cardiometabolic risk including weight gain, cardiovascular disease outcomes and diabetes only when restricted to sugar-sweetened beverages and not for sugars from other sources. In fact, sugar-sweetened beverages are a marker of an unhealthy lifestyle and their drinkers consume more calories, exercise less, smoke more and have a poor dietary pattern. The potential for overconsumption of sugars in the form of sugary foods and drinks makes targeting sugars, as a source of excess calories, a prudent strategy. However, sugar content should not be the sole determinant of a healthy diet. There are many other factors in the diet-some providing excess calories while others provide beneficial nutrients. Rather than just focusing on one energy source, we should consider the whole diet for health benefits.

Keywords Sugars $\cdot$ Fructose $\cdot$ Obesity $\cdot$ Overweight Diabetes $\cdot$ Cardiovascular disease $\cdot$ Review

\section{Introduction}

Overconsumption of dietary sugars with their potential to cause cardiometabolic disease has emerged as an important public health issue, highlighted by the vast coverage given in academic journals and the popular press. Special focus is on the fructose moiety within sugars due to the former's unique metabolic and endocrine response. Fructose-containing sugars that are 'added' to our diets are alleged to be an important risk factor for the development of obesity [1], cardiometabolic disease [2] including metabolic syndrome [3] and diabetes [4]. Leading organizations including the World Health Organization (WHO) [5] and Canadian Diabetes Association (CDA) [6] have recommended a reduction in added sugar. The case against the harms of fructose-containing sugars appears straightforward at first, 
but in reality the debate is more nuanced. It was just in recent past that saturated fat was of public health concern for its adverse effects on obesity and cardiovascular disease- though the blame has now been shifted to fructosecontaining sugars $[7,8]$. In this paper we aim to present a review of the highest level of evidence on dietary sugars and their effect on obesity and cardiometabolic disease including important considerations that sheds light on some of the controversies around this topic.

\section{Historical roots}

The story of dietary sugars and their potential harms on our health has oscillated several times over the past five decades as more scientific evidence on this topic came to light. Hence, it is important to give a brief historical background to the scientific controversy surrounding dietary sugars. The sugar debate first started in the 1970s when opposite positions were presented as explanations for the epidemic of cardiovascular disease. In the 1970, the American biochemist Ancel Keys, using his seven countries ecological study, argued for a role of saturated fat in heart disease [9], while in 1972 John Yudkin, a British nutritionist, warned in his book, 'Pure, White and Deadly' that dietary sugars were responsible for the rise in heart disease and diabetes [10]. At that time, the fat hypothesis gained general acceptance, and for the next four decades, low-fat dietary advice became part of many national nutritional guidelines with the aim of reducing the risk of chronic diseases like cardiovascular disease [11].

Dietary sugars came into forefront again in 2004 when Dr. George Bray, an eminent obesity researcher, published an ecological study that showed a parallel rise between overweight/obesity and fructose-containing sugars in the USA [12]. In an ecological study, the units of analysis are populations or groups of people rather than individuals; therefore, any conclusions derived may not apply to individuals; to do so erroneously is known as ecological fallacy [13]. It is also well recognized that an ecological study represents a very weak level of evidence [14], and Dr. Bray, rightly, presented his findings as hypothesis generating rather than causal.

Dr. Bray's study sparked a real interest in this field and kick-started a new sugar debate that has continued fiercely to this day. Dr. Robert Lustig, a paediatrician from University of California San Francisco, in 2009 made a passionate case against fructose in the popular YouTube video, 'Sugar: The bitter truth' [15] that currently (November 2016) has more than six-and-a-half million views. This YouTube video was followed by a steady increase in the number of editorials, commentaries and opinion pieces in scientific literature that denoted added fructose and its related sugars [sucrose and high-fructose corn syrup (HFCS)] as health hazards while calling for measures to restrict their intake $[1,16-20]$. In the past several years traditional and social media caught up with the scientific debate and have now published numerous popular books, mainstream documentaries and newspaper headlines portraying fructosecontaining sugars as being toxic [21-23]. The public gets a confusing message as several nutrition researchers stand in opposite camps on the harms of fructose-containing sugars debate $[24,25]$. Controversies regarding ties of researchers with the sugar industry have further fuelled the debate, e.g. it was recently reported that when writing an influential review paper that downplayed the harms of sugars several decades ago, the authors did not disclose their ties with the sugar industry [26]. It is debatable whether these ties bias the work that researchers perform; however, existence of such ties has turned a purely scientific dialogue into an intensely emotional one. It is clear that the message of the harms of sugars is much louder and dietary sugars are now squarely blamed for the rising epidemic of obesity and chronic disease in the Western nations, and with some even drawing strong parallels with tobacco [27]. The question that remains is whether, based on the best available scientific evidence, this clarion call against dietary sugars is justified?

At first glance, the case presented against sugars is quite persuasive, which hinges on implicating the fructose moiety for its unique metabolic and endocrine responses. Fructose is present in all main dietary sugars except for milk. Proponents of this fructose-centric view present ecological data, supporting it with animal studies and human mechanistic studies that show adverse effects of fructose in very high doses [28]. This evidence is backed by sound biochemical plausibility which indicates that fructose, unlike glucose, acts as an unregulated metabolic de novo substrate for fatty acid synthesis in the liver as it bypasses the main rate-limiting steps of glycolysis [29]. A new hypothesis of metabolic syndrome that involves fructose-induced increases in uric acid via the depletion of intracellular adenosine triphosphate further supports the plausibility of fructose' special metabolic role [30]. Other likely mechanisms of harm relate to fructose' unique endocrine signature, whereby fructose does not stimulate insulin, or the 'satiety hormone' leptin, nor suppresses the 'hunger hormone' ghrelin, leading to an overall impaired satiety signalling [31]. Functional magnetic resonance imaging (fMRI) studies suggest that fructose differentially stimulates hypothalamic centres associated with the regulation of food intake and reward compared with glucose [32]. Other mechanisms may relate to hedonic pathways, whereby fructose-containing sugary foods are over-consumed owing to their high palatability and an inability to compensate for the energy 
consumed in liquid form, such as sugar-sweetened beverages (SSBs) [2, 33].

It is worth noting that the bulk of the biochemical and metabolic evidence presented against fructose is based on rodent models [4, 30, 34] and human mechanistic studies $[4,32,35]$. As reviewed recently by Van Buul et al. [36], these human mechanistic studies are insufficient to demonstrate a causal role of fructose in metabolic diseases as these often involve feeding large amounts of pure fructose without concomitant glucose intake. However, fructose is commonly ingested in an almost 1:1 ratio with glucose, e.g. as the table sugar sucrose, which is a disaccharide made of the monosaccharides fructose and glucose; as fructose and glucose in high-fructose corn syrup (HFCS) found in SSBs; as fructose, glucose and sucrose found in fruit and honey. In parallel, ecological observations that link increase in fructose availability with increase in obesity, diabetes and hypertension [3, 12, 37] are offered as compelling proof that these mechanisms are indeed in operation. Even so, animal and ecological studies should only be considered to be hypothesis generating owing to their indirectness and many potential sources of bias. Moreover, extrapolation of the above mechanisms from animal models to humans needs to be done carefully, with the understanding of limitation due to biochemical and physiological differences that exist [38]. In the case of dietary sugars, it is still unclear whether the high doses given in animal models apply to the median level of fructose consumption in humans, and whether they then lead to meaningful downstream outcomes. For example, there are differences between rodents and humans on how fructose is metabolically handled in the liver. Typically, in the human liver, $50 \%$ of a fructose load is converted into glucose, $25 \%$ into lactate and approximately $15 \%$ into glycogen [39]. Stable isotope tracer studies have found that de novo lipogenesis pathway for fructose in humans is very minor $(<1 \%)$ at moderate intake and up to $5 \%$ in overfed state, but in mice livers de novo lipogenesis pathway converts typically $\sim 30 \%$ of fructose to triglycerides and reaches beyond $>50 \%$ in overfed states $[36,40]$.

Several international and national health authorities have recently changed their dietary guidelines recommending a restriction in dietary sugars intake. Is this recommendation based on evidence of harm in relation to obesity, diabetes and cardiovascular disease? A careful review of these guidelines reveals that most of these guidelines use evidence from dental harms and caloric harms associated with excess sugar, especially SSB intake. The WHO recommended added sugars to be $<10 \%$ of total daily energy intake based on observational data from dental caries [5]. This amounts to $<50 \mathrm{~g}$ (12 teaspoons) of added sugars/ day based on a typical 2000-kilocalorie diet. The term 'free sugars' (we use the equivalent term 'added sugars' throughout this paper) is defined by WHO as 'monosaccharides and disaccharides added to foods and beverages by the manufacturer, cook or consumer, and sugars naturally present in honey, syrups, fruit juices and fruit juice concentrates' [5]. This definition does not include 'intrinsic sugars', which are those 'incorporated within the structure of intact fruit and vegetables' or 'sugars from milk (lactose and galactose)'. Dietary Guidelines Advisory Committee (DGAC) that informs the US Department of Agriculture (USDA) dietary recommendations provided a similar recommendation to reduce calories from added sugars to $<10 \%$ based on dietary pattern modelling [41]. Scientific Advisory Committee on Nutrition (SACN) of the UK (UK) used clinical trial data to show that high sugar intake was associated with high energy intake-so both need to be reduced-and recommended $<5 \%$ intake of added sugars [42]. The Heart and Stroke Foundation of Canada followed the WHO recommendation, but in addition to citing evidence from dental caries, it also assessed evidence indicating that excess sugars (using SSB data from prospective cohort studies) consumption is associated with adverse health effects including heart disease, stroke, obesity, diabetes, high blood pressure, cancer to support a recommendation of $<10 \%$ dietary intake of energy from sugars [43]. Similarly, using evidence from prospective cohort studies of SSB intake on risk of obesity and diabetes, the CDA also submitted a position statement in September 2015 recommending $<10 \%$ calories to come from added sugars [6]. The Nordic Nutrition Recommendations of 2012 also called for a restriction of added sugars to be kept below $10 \%$ total energy intake [44]. The evidence used in this case was threefold: (1) restriction on added sugars will ensure adequate intake of micronutrients and dietary fibre while supporting a healthy dietary pattern, (2) SSBs are associated with an increased risk of type- 2 diabetes and excess weight gain and should, therefore, be limited, and (3) avoidance of frequent consumption of sugar-containing foods can reduce risk of dental caries. It is worth noting that in all of the above guidelines, the major focus was on restricting calories from added sugars especially in the form of SSBs, which suggests that more consideration was given to calories rather than any unique biochemical signal from fructose-containing sugars. Indeed, there was no restriction on fruits and vegetables which also contribute to fructose-containing sugars in the diet.

Dietary sugars intake has become a charged and emotive issue, both academically and in the media, and it is essential that we separate statements and opinions from the clinical evidence produced by high-quality research studies. Careful consideration should be given to the totality of evidence in this debate including the highest level of evidence from human clinical studies. It seems premature to provide human mechanistic studies as proof of harm in the absence 
of clear evidence of adverse effects of fructose on clinically meaningful outcomes. The major question that needs to be answered is: is there something special about fructose metabolism that increases the risk of obesity and chronic disease, or is the harm is related just to the excess calories it provides. In this review, we aim to present a synthesis of the highest quality evidence involving human subjects to answer this question.

\section{Level of evidence}

Figure 1 shows the hierarchy of evidence, initially developed by the Canadian Task Force on the Periodic Health Examination to help decide on priorities when searching for studies to answer clinical questions [45] and was subsequently adopted by the US Preventive Services Task Force [46]. This evidence-based framework represents a universally recognized accepted standard that informs public health policy and clinical practice guidelines, and it shows that the best source of evidence comes from randomized controlled trials (RCTs) because they offer the best protection from bias [47]. The only level of observational evidence that informs public health policy and clinical practice guidelines is prospective cohort studies, and we will start our presentation from this level of evidence.

\section{Evidence from prospective cohort studies}

Prospective cohort studies are characterized by a longterm longitudinal follow-up, good measurement of dietary exposures, superior ascertainment of incidence of disease and mortality outcomes (and not just surrogate markers) and the ability to adjust for multiple confounding factors [48]. These advantages enable prospective cohort studies to present some of the strongest evidence from observational studies for assessing the relation of dietary sugars exposure to obesity, diabetes and cardiovascular disease. While this makes prospective cohort studies a good place to look at the question of sugars and incidence of disease, drawing clear inferences from prospective cohort studies is somewhat complicated by the form in which fructose-containing sugars are consumed as the majority of evidence is available only from SSBs.

A WHO-commissioned systematic review and metaanalysis of prospective cohort studies did not find any association between total fructose-containing sugars and body weight [49]. Similarly, large prospective cohort studies have not shown any association with diabetes [50], hypertension [51] and coronary heart disease (CHD) [52]. One exception is gout where it was associated with fructose consumption in a systematic review and meta-analysis of prospective cohort studies [53].

Regular consumption of SSBs indicates that it can lead to weight gain and substantially increase risk of developing cardiometabolic diseases [54]. A WHO-commissioned systematic review and meta-analysis of 38 prospective cohort studies showed a significant association between SSBs and the risk of overweight/obesity in children and weight gain in adults [49]. Another meta-analysis of 22 prospective cohort studies found similar results in both children and adults [55]. In like manner, a systematic review and metaanalysis of 17 prospective cohort studies showed a similar adverse association between SSBs and incident diabetes [56]. Significant relationship of SSBs also exists with metabolic syndrome [57], hypertension [58], CHD [59, 60], stroke [61] and gout [62].

Meanwhile, pooled analyses involving many of the same prospective cohort studies that were used in the analysis of SSBs did not find harmful relationships between type 2 diabetes and total dietary sources of sugars (liquid or solid),

Fig. 1 Hierarchy of evidence in evidence-based medicine

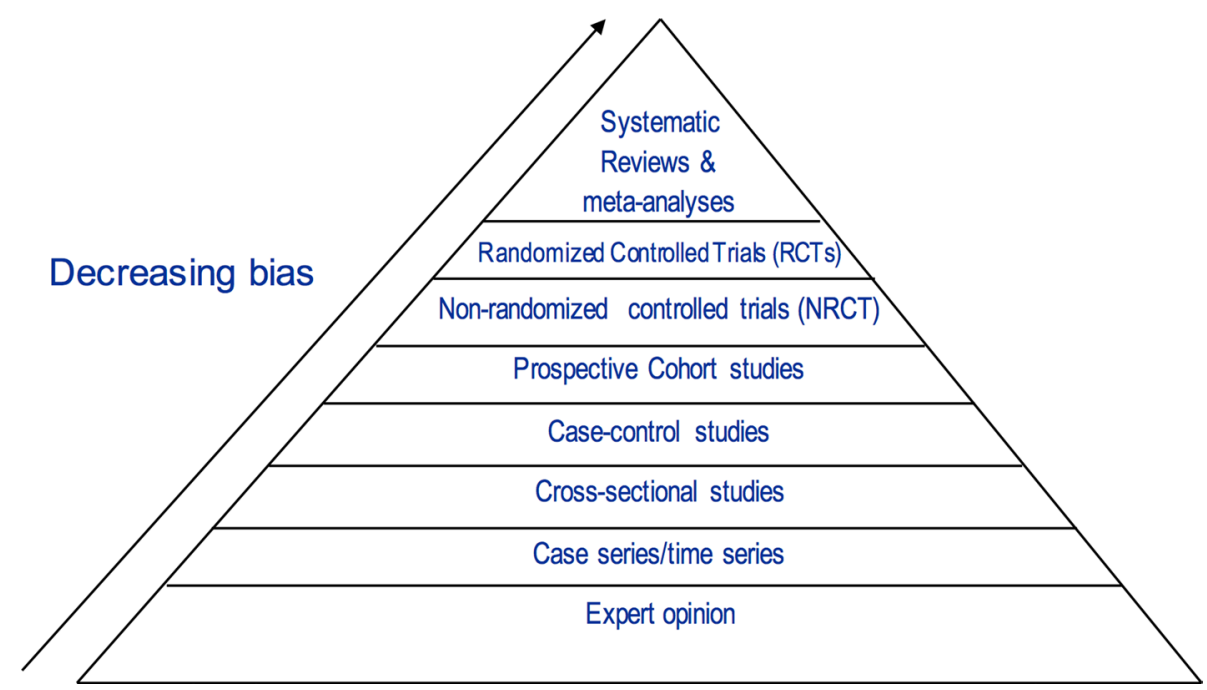




\begin{tabular}{|c|c|c|c|c|c|c|c|}
\hline Source & $\begin{array}{c}\text { Cohort } \\
\text { comparisons }\end{array}$ & Participants & Cases & $\begin{array}{c}\text { Median } \\
\text { Follow-up }\end{array}$ & Risk ratios $(95 \% \mathrm{Cl})$ & & $I^{2}$ \\
\hline \multicolumn{8}{|l|}{ Foods } \\
\hline SSBs [54] & 9 & 310,819 & 15,043 & $10 y$ & $1.26(1.12,1.41)$ & $1 \longrightarrow$ & $66 \% *$ \\
\hline SSBs (fruit drinks) [61] & 4 & 191,686 & 12,375 & $19 y$ & $1.28(1.04,1.59)$ & $\longrightarrow$ & $43 \%$ \\
\hline $100 \%$ Fruit juice [64] & 4 & 137,663 & 4,906 & $10 y$ & $1.03(0.91,1.18)$ & $\rightarrow$ & $6 \%$ \\
\hline Yogurt [64] & 8 & 187,170 & 15,893 & $10 y$ & $0.86(0.75,0.98)$ & $\multimap$ & $59 \% *$ \\
\hline Sherbet [64] & 2 & 78,437 & 2,846 & $11 y$ & $0.90(0.79,1.03)$ & $\rightarrow$ & $0 \%$ \\
\hline Ice Cream [64] & 2 & 78,437 & 2,846 & $11 y$ & $0.83(0.73,0.95)$ & $\leadsto$ & $0 \%$ \\
\hline Cakes, cookies [62] & 8 & 16,154 & 778 & $16 y$ & $0.96(0.86,1.07)$ & -1 & $35 \%$ \\
\hline Cereal (whole grain) [63] & 3 & 128,314 & 4,202 & $10 y$ & $0.72(0.55,0.93)$ & $\longrightarrow$ & $78 \%$ \\
\hline Fruits [66] & 11 & 424,677 & 22,995 & $11 y$ & $0.93(0.88,0.99)$ & $y$ & $0 \%$ \\
\hline \multicolumn{8}{|l|}{ Sugars } \\
\hline Total sugars [60] & 13 & 109,651 & 13,906 & $12 y$ & $0.900 .73,1.12)$ & + & $90 \% *$ \\
\hline Total sucrose [60] & 7 & 175,360 & 3,829 & $6 y$ & $1.0(0.90,1.1)$ & - & $50 \% *$ \\
\hline \multirow[t]{3}{*}{ Total fructose [60] } & 7 & 129,480 & 3,613 & $9 y$ & $1.0(0.90,1.1)$ & 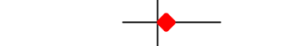 & $50 \% *$ \\
\hline & & & & & 0 & 1.5 & 2 \\
\hline & & & & & & Benefit & \\
\hline
\end{tabular}

Fig. 2 Sources of sugars and incident type 2 diabetes. Adapted from [68]. Summary estimates (diamonds) were derived from pooled risk ratios for comparison of extreme quantiles (the highest level of exposure compared with the lowest level of exposure). The one exception was for cakes and cookies, which compared the highest level of expo-

total sucrose, total fructose [63] or other sources of added fructose such as $100 \%$ fruit juice [64] and cakes and cookies [65]. In fact, some sources of sugars including wholegrain cereals [66], yogurt [67] and ice cream [67] showed a positive benefit with type 2 diabetes (see Fig. 2). This does not necessarily mean that ice cream might be beneficial for type 2 diabetes, but highlights the complexity of the relationship between the dietary source of sugars and disease outcomes [68]. To make matters even more complex, another important source of fructose-containing sugars, fruits and vegetables, has consistently shown to reduce the risk of type 2 diabetes [69], CHD and total mortality [70] in pooled analyses of large prospective cohort studies.

\section{Are sugar-sweetened beverages a special case?}

The contrast of results between sugars provided by SSBs and sugars from other food sources is striking; the former shows a consistent signal of harm, while the latter shows either no harm or a benefit. These results suggest that sugars from SSBs might be a special case and this assertion is supported by several plausible explanations. One, the association might be related to energy as the observed associations between SSBs and cardiometabolic diseases only remain significant at the highest quantiles of exposures and do not remain significant at mean levels of exposures for USA, the exception being gout [53]. The disappearance or sure with the middle level of exposure; the reference exposure that was associated with the lowest risk. Data are expressed as risk ratios with $95 \%$ CIs. Asterisks indicate significant interstudy heterogeneity as assessed by the Cochran $Q$ statistic and quantified by the $I^{2}$ statistic at a significance level of $P<.10$. SSBs sugar-sweetened beverages

marked attenuation of the effect of SSBs on weight gain after adjustment for total energy in one meta-analysis [55] and on diabetes risk after adjustment of adiposity [56], a proxy of high caloric intake, in another meta-analysis suggests that the effect of SSBs on cardiometabolic diseases appears to be highly mediated by energy. Two, it is possible that liquid calories from SSBs beverages are poorly compensated for by a decrease in total energy intake compared to solid calories, leading to weight gain and downstream cardiometabolic diseases. This hypothesis, however, remains unproven compared to acute preload trials which show that liquid calories were less compensated than solid calories [33]. Long-term trials on this subject designed to assess whether this lack of compensation results in weight gain have been inconclusive $[71,72]$. In contrast to SSBs, liquid calories from $100 \%$ pure fruit juice have also not shown reliable associations with diabetes or cardiometabolic diseases [56, 64]. Three, SSBs are easier to measure in research studies, e.g. number of cans of sweetened beverages like Coca-Cola can be recalled with precise fidelity, which is not the case for other sources of fructose-containing sugars. The latter are usually estimated from individual foods leading to increased measurement error due to the imprecise nature of portions and the actual content of sugars. Four, compared to SSBs, others sugar sources include nutrient-dense fruits and vegetables as well as whole-grain products that contain potential health-enhancing nutrients, fibre and phytochemicals. In fact, these sources of sugars 
have been associated with weight loss and improved metabolic outcomes in large prospective cohort studies [69, 70, 73] and randomized dietary trials [74, 75] and, as such, may balance any harms associated with sugars. Five, SSBs might be a marker of an unhealthy lifestyle. Individual foods and lifestyle choices do not exist in isolation, and an approach that only looks at them individually may be inadequate for disentangling complicated interactions between different foods and dietary and lifestyle patterns in real-world situations. In this regard, it has been shown that sugar-sweetened beverage consumers are different from those who do not consume sugary drinks; the former snack more, consume more calories, smoke more, exercise less and have a worse dietary pattern [59, 76, 77]. Such lifestyle and dietary factors are generally adjusted for in the analyses of prospective cohort studies as they may confound the association between sugar-sweetened beverages and disease outcomes. However, it is well recognized that complete correction of such confounding variables is not possible due to residual confounding. Such variables might not be measured, measured imprecisely or not adjusted at all as the total number of confounders is unknown [78-80]. While these important collinear effects between such lifestyle factors and SSBs might bias the results in prospective cohort studies, such collinear effects can be exploited to an advantage by taking a larger snapshot using dietary patterns.

Analysis of food consumption as dietary patterns offer a more comprehensive approach to the relationship between diet and disease and as such might shed a light on what foods, which might in themselves be associated with disease, are taken along with SSBs. The Harvard cohorts (Nurses' Health Study, the Nurses' Health Study II and the Health Professionals Follow-up Study) have revealed two distinct dietary patterns. One is the Western dietary pattern, which is characterized by high intakes of SSBs, processed meats, red meats, refined grains, French fries, sweets and desserts, and the second is the prudent dietary pattern characterized by high intakes of vegetables, fruit, legumes, fish, poultry and whole grains. The Western dietary pattern is associated with increased cardiometabolic disease outcomes that includes weight gain, increased risk of diabetes, CHD and mortality resulting from CHD in energy-adjusted models [81-83]. In fact, the weight gain associated with a Western dietary pattern [83] appears to be greater compared to the weight gain associated with SSBs alone [84, 85]. Each individual food component of the Western dietary pattern also has a greater relative risk of diabetes $(\mathrm{RR}=2.56-2.93)[86-89]$ and $\mathrm{CHD}(\mathrm{RR}=1.46)[90]$ than those reported for SSBs alone $(\mathrm{RR}=1.01-1.18$, per serving) $[49,55-60]$. Moreover, these effects on bodyweight of the Western dietary pattern persist even after adjustment for sugar-sweetened beverage intake in studies in which this adjustment was made $[83,86]$ suggesting that the Western dietary pattern as a whole is a more important factor contributing to increased energy intake and weight gain, compared to SSBs alone.

There are some important caveats to the clear and consistent relationship between SSBs and cardiometabolic disease. The associations for SSBs are only significant when comparing extreme comparisons, i.e. typically $\geq 1-2$ servings/day versus none or $<1$ serving/month, or an increase in energy consumption from each additional serving/day. No significant associations have been seen at moderate levels of intake $[49,59,61,62,91]$, which are around the mean estimated global intake of SSBs 0.58 servings/day [92] or approximately $15 \mathrm{~g}$ of added sugars/day.

How does a moderate consumption of SSBs contribute to the burden of disease at a global level? The recent Global Burden of Disease Study used national level data on 67 measured risk factors for disease including SSB consumption worldwide [93]. The authors estimated global, regional and national disease burdens using best available estimates of the association of each risk factor with obesity, diabetes mellitus, cardiovascular disease and cancers, and combined it with age-, sex- and cause-specific mortality using a comparative risk assessment analytic framework [94]. For SSBs, these estimates included both direct effects on disease burden but also indirect effects via increased obesity. When looking at the ranking of the top 15 dietary and physical activity factors, high intake of SSBs was ranked only 12 th for its burden on total global mortality and was the only risk factor with added sugars [93]. High blood pressure, tobacco smoking, household air pollution, diet low in fruits and alcohol use were ranked $1-5$, respectively, as the leading global risk factors for attributable burden of disease. In comparison, high intake of SSBs was ranked all the way down at number 32nd globally for attributable burden of disease. When counting total estimated deaths, the authors found that in 2010, dietary risk accounted for an estimated 11.3 million deaths worldwide [93], but SSBs only accounted for an estimated $184 \mathrm{k}$ deaths $(1.6 \%$ of total deaths attributed to dietary risk) [94]. In only a few countries SSBs accounted for a much larger share of disease burden due to higher average consumption, e.g. Mexico had the largest absolute (405 deaths/million) and proportional mortality attributable to SSBs $(12.1 \%)$, with one of the highest mean intakes (2.6 servings/day), but such a high intake is an exception and not the norm across the globe as 90 per cent of countries had an average SSB intake of $<1$ serving/day [92]. USA also had a relatively high average consumption of SSBs (1.3 servings/day; $42.9 \mathrm{~g} /$ day added sugars) but that contributed only $2.3 \%$ of proportional mortality [94]. This study underscored that compared to other risk factors, SSBs play a relatively minor role in global disease burden. 
If we take a look at the potential risk of individual diseases, the effect sizes associated with SSBs tend to be relatively modest. For example, pooled relative risk (RR) for SSBs with cardiometabolic diseases including metabolic syndrome ( $R R=1.20$, highest vs. lowest quantile) [57], diabetes $(\mathrm{RR}=1.18$, per serving increase) [56], hypertension ( $\mathrm{RR}=1.12$, highest vs. lowest quantile) [58], CHD ( $R R=1.17$, highest vs. lowest quantile) [60], stroke ( $\mathrm{RR}=1.06$, per serving increase) [95] is relatively modest and did not exceed 1.20. Focusing on type 2 diabetes, the risk estimate of SSBs intake is similar to or even lower than those of other established dietary risk factors, processed meats $(\mathrm{RR}=1.51,100 \mathrm{~g} /$ day $)$ [96], red meat $(\mathrm{RR}=1.19,50 \mathrm{~g} /$ day) $[96,97]$, French fries ( $R R=1.16$, two servings/week) [98]; high glycaemic index $(\mathrm{RR}=1.33$, highest vs. lowest quantile) [99], fried food ( $\mathrm{RR}=1.55,<1$ vs. $>7$ time a week) [100] and potatoes ( $R R=1.18$, one serving/day) [98]. When we look beyond dietary factors, the association of SSBs with type 2 diabetes pales in comparison. The association of body mass index (lowest versus highest levels) with type 2 diabetes ranges from 10 to 30 times [101], which is similar to risk levels associated with long-term smoking and lung cancer [102]. As these risk ratios are several fold higher than the risk estimates seen with SSB intake, the analogy that SSBs are to obesity and diabetes as cigarette smoking to lung cancer [27, 103, 104] does not stand. Thus, the evidence suggests that similar to other dietary factors, the association of SSBs with diabetes is modest and it cannot be singled out and put in the bracket of other non-dietary factors.

The relatively modest risk ratios of the association of per serving increase in SSB intake with cardiometabolic diseases begs the question, if other sources of calories in the diet are more important than SSBs? A pooled analyses of the three Harvard cohorts by Mozaffarian et al. [105] found that the weight gain observed for every 4 years of follow-up for increasing one serving of sugary beverages was smaller than or in range of increasing one serving of several other foods such as French fries, potato chips, unprocessed meat, processed meat, trans fat or boiled, baked or mashed potatoes when not adjusted for energy (see Fig. 3). It is likely that extra calories are driving this association of SSBs with weight gain, which suggests that SSBs provide fewer calories than the above foods.

Overall, the evidence we presented suggests that SSBs have comparatively small effect sizes seen only at the extremes of intake, which makes them an important source of excess sugary calories but not something that unusually contributes to increased cardiometabolic risk compared to many other aspects of the diet when we consider their mean intake globally.

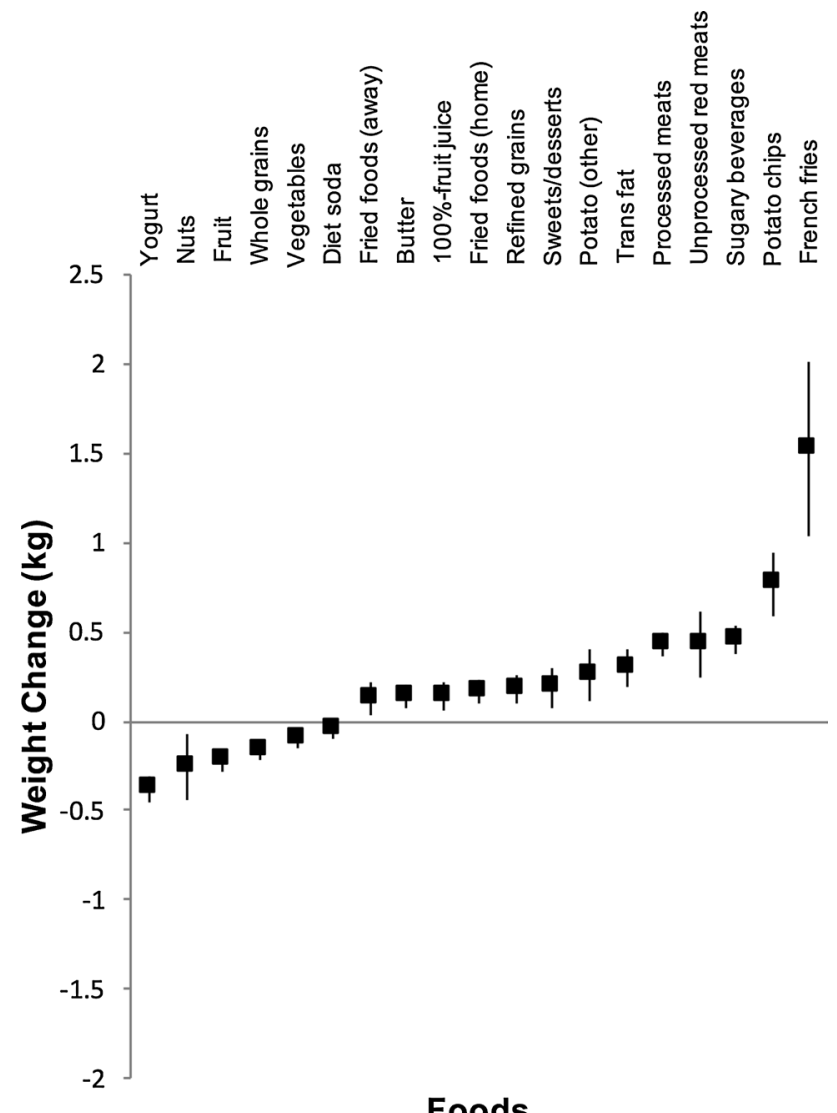

Foods

Fig. 3 Bodyweight changes $(\mathrm{kg})$ over a 4-year period associated with an increase in the consumption of different food items. Using data from the Nurses' Health Study, the Nurses' Health Study II and the Health Professionals Follow-up Study as reported by Mozaffarian et al. [105]. Increased consumption is based on servings/day for all items except trans fat (per cent total energy) and fried foods (servings/week). Data represent pooled mean changes with $95 \%$ confidence intervals adjusted for age, baseline body mass index at the start of each 4-year interval, sleep duration and changes in physical activity, smoking, alcohol use, television watching and each additional food item

\section{Evidence from controlled trials}

High-quality evidence from randomized and non-RCTs offers the best protection from bias as these control for confounding factors while allowing for the isolation of the effect of interest. The major limitation of nutrition trials of dietary sugars is the lack of clinical outcomes as these require long-term follow-up over years and most nutrition trials last only a few weeks. However, risk factors or surrogate outcomes measured at intermediate times can be explored with good precision, thereby providing insight into processes that might lead to disease. 


\section{Fructose and cardiometabolic risk factors}

We can use two types of trial designs together to disentangle the direct association of various risk factors with fructose intake from the energy it provides. One, substitution trials, in which comparisons are matched for energy, with fructose, in liquid or mixed format, is substituted for other sources of carbohydrates in the diet. The substitution trials can provide information on the usefulness of lowsugar foods on shelves, which are usually backfilled with other carbohydrates including starch and maltodextrins, so in many cases the total amount of calories do not change [106]. The second type of trials is addition trials, in which comparisons are supplemented with excess energy from fructose compared with the same diet alone without excess energy, i.e. they are hypercaloric. These trials together provide information on whether it is the excess energy from fructose that leads to adverse effects.

In a Canadian Institute of Health Research (CIHR) funded series of systematic reviews and meta-analyses of controlled trials consisting of more than 50 trials and an excess of 1000 subjects, we examined the effect of fructose on various cardiometabolic risk factors when it was provided in isocaloric substitution for other carbohydrates (see Fig. 4). In the pooled analysis of the substitution trials we found no adverse effect on body weight [107], fasting lipids

\begin{tabular}{|c|c|c|c|c|c|c|c|}
\hline \multirow{2}{*}{$\begin{array}{l}\text { Cardiometabolic endpoint } \\
\text { Body weight [104] }\end{array}$} & & \multirow{2}{*}{$\begin{array}{c}\text { Comparisons } \\
31\end{array}$} & \multirow{2}{*}{$\frac{\text { No. }}{637}$} & \multicolumn{3}{|c|}{ Standardized Mean Difference (SMD) with $95 \% \mathrm{Cl}$} & \multirow{2}{*}{$\frac{12}{37 \%^{*}}$} \\
\hline & & & & $-0.22(-0.58,0.13)$ & & $\rightarrow$ & \\
\hline \multirow[t]{5}{*}{ Fasting Lipids [106] } & LDL-C & 26 & 327 & $0.36(-0.27,0.50)$ & & 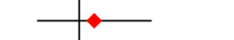 & $11 \%$ \\
\hline & Apo-B & 8 & 176 & $-0.21(-0.96,0.43)$ & & $\rightarrow-$ & $62 \% *$ \\
\hline & Non-HDL-C & 26 & 457 & $0.09(-0.30,0.47)$ & & $\rightarrow$ & $92 \%{ }^{*}$ \\
\hline & TG & 49 & 815 & $0.08(-0.20,0.36)$ & & - & $62 \%{ }^{*}$ \\
\hline & HDL-C & 27 & 525 & $0.00(-0.38,0.38)$ & & 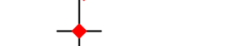 & $49 \% *$ \\
\hline Postprandial TG [111] & & 14 & 290 & $0.14(-0.02,0.30)$ & & $\Rightarrow$ & $54 \%{ }^{*}$ \\
\hline \multirow[t]{3}{*}{ Glycemic control [109] } & GBP & 19 & 277 & $-0.28(-0.45,-0.11)$ & & $\star$ & $56 \% *$ \\
\hline & FBG & 47 & 881 & $-0.04(-0.34,0.26)$ & & - & $78 \% *$ \\
\hline & FBI & 34 & 622 & $-0.25(-0.60,0.09)$ & & $\rightarrow-$ & $70 \% *$ \\
\hline \multirow[t]{3}{*}{ Insulin sensitivity [109] } & Whole body & 16 & 265 & $-0.21(-0.42,0.01)$ & & - & $66 \%{ }^{*}$ \\
\hline & Hepatic & 3 & 25 & $0.42(-0.25,1.09)$ & & & $51 \%$ \\
\hline & HOMA-IR & 39 & 806 & $0.09(-0.03,0.20)$ & & $p$ & $66 \%{ }^{*}$ \\
\hline \multirow[t]{3}{*}{ Blood pressure [107] } & SBP & 13 & 352 & $-0.39(-0.93,0.16)$ & & $\rightarrow$ & $31 \%$ \\
\hline & DBP & 13 & 352 & $-0.68(-1.23,-0.14)$ & & $\longrightarrow-$ & $47 \%{ }^{*}$ \\
\hline & MAP & 13 & 352 & $-0.64(-1.19,-0.10)$ & & $\multimap$ & $97 \%{ }^{*}$ \\
\hline Uric acid [108] & & 18 & 390 & $0.04(-0.43,0.50)$ & & & $0 \%$ \\
\hline \multirow[t]{4}{*}{ NAFLD [112] } & IHCL & 4 & 95 & $-0.09(-0.36,0.18)$ & & 1 & $0 \%$ \\
\hline & ALT & 6 & 164 & $0.07(-0.73,0.87)$ & & $\longrightarrow$ & $0 \%$ \\
\hline & & & & -4 & $\begin{array}{ll}1 & -2\end{array}$ & 12 & 3 \\
\hline & & & & & Benefit & Harm & \\
\hline
\end{tabular}

Fig. 4 Substitution trials. The meta-analyses are of isocaloric substitution trials, in which fructose was exchanged for other carbohydrate sources under energy-matched conditions. Summary estimates (diamonds) were derived from pooled trial-level data. To allow the summary estimates for each endpoint to be displayed on the same axis, mean differences were transformed to standardized mean differences (SMDs). Pseudo-95\% CIs for each transformed SMD were derived directly from the original mean difference and $95 \%$ CI. The scales were also flipped for high-density lipoprotein cholesterol (HDLC), whole-body insulin sensitivity and hepatic insulin sensitivity so that the direction of the effect for benefit or harm was in the same direction as that for the other endpoints. Asterisks indicate signifi- cant interstudy heterogeneity as assessed by the Cochran $Q$ statistic and quantified by the $I^{2}$ statistic at a significance level of $P<.10$ (the higher significance level was chosen owing to the poor sensitivity of the test). $A L T$ alanine aminotransferase, $A p o-B$ apolipoprotein B, $D B P$ diastolic blood pressure, $F B G$ fasting blood glucose, $F B I$ fasting blood insulin, GBP glycated blood proteins, HOMA-IR homoeostatic model assessment-insulin resistance, $I H C L$ intrahepatocellular lipid, $L D L-C$ low-density lipoprotein cholesterol, MAP mean arterial pressure, $S B P$ systolic blood pressure, $T G$ triglycerides, No. total number of participants included in the meta-analysis of the controlled dietary trials 
[108, 109], blood pressure [110], uric acid concentration [111], glycaemic control and insulin sensitivity [112, 113], postprandial lipids [114] and markers of non-alcoholic fatty liver disease (NAFLD) [115] in individuals with varying metabolic phenotypes. In the above studies, the dose of fructose ranged from a moderate 22.5 to $300 \mathrm{~g} /$ day with the follow-up ranging from one to 52 weeks. In these studies, fructose shows a slight benefit for glycaemic control and blood pressure when isocalorically exchanged for other sources of carbohydrates [110, 112, 113]. The improvement in glycaemic control as assessed by glycated blood proteins was equivalent to $0.57 \%$ reduction in haemoglobin A1c [112, 113], which is at the lower limit of efficacy of oral antihyperglycaemic agents of $0.5 \%$ [116] and exceeds the US Food and Drug Administration's threshold of $0.3 \%$ for the development of new oral antihyperglycaemic agents both in individuals with and without diabetes [117]. Furthermore, in a previous meta-analysis, the effect of fructose on HbA1c has been found to be dose dependent [118] which gives credence to the above results. In short, these substitution studies demonstrate that if we match calories with other carbohydrates, fructose is not associated with an increased harm for cardiometabolic parameters and may even be beneficial in low doses.

Conversely, the adverse effect of fructose in isocaloric trials is seen only under certain conditions. The dose threshold of harm for the effect of fructose on fasting triglycerides has been reported as $>60 \mathrm{~g} /$ day in people with type 2 diabetes and $>100 \mathrm{~g} /$ day in those with mixed phenotypes, and a threshold of $>50 \mathrm{~g} /$ day for postprandial triglycerides in those with mixed phenotypes [107, 118]. From pooled and individual controlled trials, the only condition in which isocaloric comparisons of fructose were found to be associated with increase in both fasting and postprandial triglycerides was when very high doses (>100 g/day) of fructose were provided [119, 120]. However, these findings have not been reproduced in dose-response and subgroup analyses in updated systematic reviews and meta-analyses [108, 114].

Why would fructose show benefit on HbA1c or glycated haemoglobin in low doses? Fructose might be needed in smaller amounts as it is sweeter than glucose. The relative sweetness in a $10 \%$ solution for fructose is 117 , glucose is 65 , and sucrose is 100 [121]. Although, in nature, fructose is always present along with glucose, a median higher sweetness with fructose compared to glucose would probably not lead to larger intakes. Moreover, biological evidence suggests that fructose might assist in the metabolic handling of glucose. Fructose has a very low glycaemic index of 14 compared to glucose $(=100)$ and sucrose $(=65)$ [122] which might lower HbA1c levels. However, such an affect is not seen at very high dose of fructose, where it impairs insulin sensitivity driving up HbA1c [118]. The low glycaemic index of fructose also led to an early interest for its role in diabetes management. Emerging evidence also suggests that low-dose fructose (approx. $10 \mathrm{~g} / \mathrm{meal}$ equal to one apple) may benefit glycaemic control through its metabolite fructose-1-phosphate by inducing glucokinase activity [123]. In vitro studies in cultured hepatocytes demonstrate that fructose-1-P, a fructose metabolite, displaces fructose-6-P from the regulatory glucokinase-binding protein in the nucleus, causing the translocation of glucokinase to the cytosol. Glucosidase in turn increases the phosphorylation of incoming glucose and suppression of endogenous glucose production [124-127]. This catalytic effect of fructose has been reported in vivo also, where a reduction in hepatic glucose production under hyperglycaemic clamp conditions was seen in patients with type 2 diabetes and an increase in glycogen synthesis by carbon-13 nuclear magnetic resonance spectroscopy under euglycaemic clamp conditions was found in participants without diabetes [123, 128]. Similarly, these catalytic effects are also seen acute clinical studies. Catalytic doses of fructose at 7.5-10 g have shown to reduce postprandial glycaemic response to high glycaemic index meals like oral glucose or mashed potatoes in healthy participants [129, 130] and those with type 2 diabetes [131]. These mechanisms also appear to be sustainable over long-term intake of fructose. Our systematic review and meta-analysis of controlled trials on the effect of small catalytic fructose doses $(\leq 36 \mathrm{~g} /$ day) in exchange for starch showed similar glycaemic benefits as those in higher doses without any adverse effects on metabolic control over 1-52 weeks of follow-up [113]. Furthermore, in our re-analysis of glycaemic control trials, fructose-containing sugars showed harm in hypercaloric trials but demonstrated a strong protective effect in isocaloric trials [132]. These findings suggest that the metabolic effect of sugars should be considered separately from their caloric effects.

Similar to rodent studies of overfeeding where we see a consistent signal for harm [34], in humans a signal for harm is found in hypercaloric addition trials in which fructose is added to provide excess calories in the diet and compared to the same diet without the excess calories. Systematic reviews and meta-analysis of such trials have shown that fructose intake providing excess calories is associated with weight gain [107], increase in fasting [108, 109] and postprandial triglyceride levels [114], fasting glucose levels and insulin resistance [112, 113], uric acid concentrations [111] and markers of NAFLD [115] (see Fig. 5). The inability of fructose to demonstrate the same adverse associations in isocaloric substitution for other carbohydrates suggests that the primary determinant of these observed harms is excess calories rather than any unusual metabolic or endocrine response to fructose. Thus, the adverse effects observed under conditions of overfeeding appear to be no more 


\begin{tabular}{|c|c|c|c|c|c|c|c|}
\hline Cardiometabolic end point & & Comparisons & No. & Standardized Mean & Difference (SMD) & with $95 \% \mathrm{Cl}$ & $I^{2}$ \\
\hline Body weight [104] & & 10 & 119 & $1.24(0.61,1.85)$ & & $\longrightarrow-$ & $30 \%$ \\
\hline \multirow[t]{5}{*}{ Fasting Lipids [106] } & LDL-C & 4 & 79 & $0.14(-0.39,1.57)$ & & 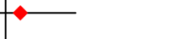 & $77 \%^{*}$ \\
\hline & Apo-B & 2 & 48 & $2.00(0.55,3.33)$ & & & $0 \%$ \\
\hline & Non-HDL-C & 2 & 43 & $0.30(-1.11,1.66)$ & 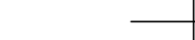 & 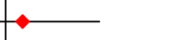 & $93 \%^{*}$ \\
\hline & TG & 8 & 125 & $1.20(0.51,1.89)$ & & $\longrightarrow$ & $66 \%^{*}$ \\
\hline & HDL-C & 4 & 79 & $-0.41(-1.39,0.57)$ & $\longrightarrow$ & - & $0 \%$ \\
\hline Postprandial TG [111] & & 2 & 32 & $0.65(0.30,1.01)$ & & - & $22 \%$ \\
\hline \multirow[t]{3}{*}{ Glycemic control [109] } & GBP & 2 & 31 & $-0.33(-0.62,-0.04)$ & $\rightarrow-$ & & $0 \%$ \\
\hline & FBG & 8 & 98 & $1.25(0.59,1.98)$ & & $\longrightarrow$ & $59 \%^{*}$ \\
\hline & $\mathrm{FBI}$ & 8 & 98 & $0.50(-0.19,1.19)$ & & $\rightarrow$ & $41 \%$ \\
\hline \multirow[t]{3}{*}{ Insulin sensitivity [109] } & Whole body & 7 & 74 & $0.25(0.12,0.39)$ & & $\bullet$ & $0 \%$ \\
\hline & Hepatic & 3 & 31 & $0.38(0.01,0.75)$ & & - & $0 \%$ \\
\hline & HOMA-IR & 9 & 113 & $0.26(-0.01,0.52)$ & & - & $77 \% *$ \\
\hline Blood pressure [107] & MAP & 2 & 24 & $-0.76(-2.15,0.62)$ & 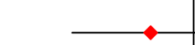 & - & $24 \%$ \\
\hline Uric acid [108] & & 3 & 35 & $2.26(1.13,3.39)$ & & 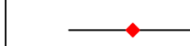 & $0 \%$ \\
\hline \multirow[t]{4}{*}{ NAFLD [112] } & $\mathrm{IHCL}$ & 5 & 60 & $0.45(0.18,0.72)$ & & $\leftrightarrow$ & $51 \% *$ \\
\hline & $\mathrm{ALT}$ & 4 & 59 & $0.99(0.01,1.97)$ & & 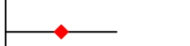 & $28 \%$ \\
\hline & & & & -4 & $\begin{array}{lll}-3 & -2 & -1\end{array}$ & $\begin{array}{lll}1 & 2 & 3\end{array}$ & 4 \\
\hline & & & & & Benefit & Harm & \\
\hline
\end{tabular}

Fig. 5 Addition trials. The meta-analyses are of hypercaloric addition trials, in which excess calories from fructose were added to a diet compared with the same diet without the excess calories. Summary estimates (diamonds) were derived from pooled trial-level data. To allow the summary estimates for each endpoint to be displayed on the same axis, mean differences were transformed to standardized mean differences (SMDs). Pseudo-95\% CIs for each transformed SMD were derived directly from the original mean difference and 95\% CI. The scales were also flipped for high-density lipoprotein cholesterol (HDL-C), whole-body insulin sensitivity and hepatic insulin sensitivity so that the direction of the effect for benefit or harm was in the same direction as that for the other endpoints. Asterisks indicate sig-

mediated by fructose than by other sources of carbohydrate used to replace it. Also, that these adverse effects appear to be reversible by exercise suggests that such adverse effects of fructose overfeeding may not be applicable to those who engage in regular physical activity $[120,133]$.

\section{Fructose-containing sugars and weight}

A criticism that can be levelled on the systematic reviews and meta-analyses of controlled trials of fructose described above is that in diet pure fructose is not consumed in isolation but is commonly consumed together with glucose, either in form of HFCS or honey, or as part of the sucrose molecule. In other words, it can be argued that the above nificant interstudy heterogeneity as assessed by the Cochran $Q$ statistic and quantified by the $I^{2}$ statistic at a significance level of $P<.10$ (the higher significance level was chosen owing to the poor sensitivity of the test). $A L T$ alanine aminotransferase, $A p o-B$ apolipoprotein $\mathrm{B}$, $D B P$ diastolic blood pressure, $F B G$ fasting blood glucose, $F B I$ fasting blood insulin, GBP glycated blood proteins, HOMA-IR homoeostatic model assessment-insulin resistance, $I H C L$ intrahepatocellular lipid, $L D L-C$ low-density lipoprotein cholesterol, MAP mean arterial pressure, $S B P$ systolic blood pressure, $T G$ triglycerides, No. total number of participants included in the meta-analysis of the controlled dietary trials

studies do not represent real-world situations for the vast majority of people. For this reason, we investigated the trials of fructose-containing sugars (HFCS, sucrose, honey, etc.) found normally in the diet and examined their effects on cardiometabolic outcomes. To allow the direct effects of fructose-containing sugars to be disentangled from calories, four types of study designs can be described: (1) substitution trials, in which fructose-containing sugars added to foods and beverages are compared with other macronutrient sources under energy-matched conditions; (2) addition trials, in which fructose-containing sugars supplemented a diet with excess energy compared to the same diet supplemented with the equivalent amounts of non-caloric food and beverages or the same diet alone without the excess energy from fructose-containing sugars; (3) subtraction 
trials, in which energy from fructose-containing sugars was reduced through displacement with water and/or nocalorie or low-calorie sweeteners or by eliminating it altogether from the background diet; and (4) ad libitum trials, in which energy from fructose-containing sugars was freely replaced with other foods like complex carbohydrates and fat without any strict control of either the study foods or the background diet.

Two separate systematic reviews and meta-analyses of substitution trials showed no difference for fructose-containing sugars on bodyweight when they were replaced isocalorically with other macronutrient sources (usually starch or other sugars) (see Fig. 6). The first one was a WHOcommissioned systematic review and meta-analysis of 13 RCTs involving 144 adults [49]. It found that total fructose-containing added sugars (predominantly sucrose) did not affect bodyweight when substituted for other sources of carbohydrates (predominantly starch). Our own pooled analysis of 31 randomized and non-randomized controlled dietary trials assessing the effect of consumption of chronic fructose-containing sugars in substitution for other sources of carbohydrates (mainly starch) under energy-matched conditions did not support an adverse effect of fructose on body weight in 637 adults [107]. Similar effects persisted even when fructose was provided in liquid form and also under condition of positive energy balance. When we restricted the analysis to five 'substitution' trials with a positive energy balance but energy matched between the arms, there was still no evidence that fructose affects bodyweight differently compared to other carbohydrates.

A follow-up systematic review and meta-analysis by the same WHO group showed mixed effects of fructosecontaining added sugars on other cardiometabolic risk factors [134]. In this paper the authors showed that in isocaloric comparisons with other sources of macronutrients, mainly starch, the fructose-containing sugars had beneficial effects on high-density lipoprotein cholesterol (HDLC) but adverse effects on triglyceride levels, low-density lipoprotein cholesterol (LDL-C) and total cholesterol levels. Fructose-containing sugars had no effect on systolic or diastolic blood pressure. While the paper findings present a good case against fructose-containing sugars, there are issues which limit their generalization. One, the author's definition of sugars included non-fructose-containing

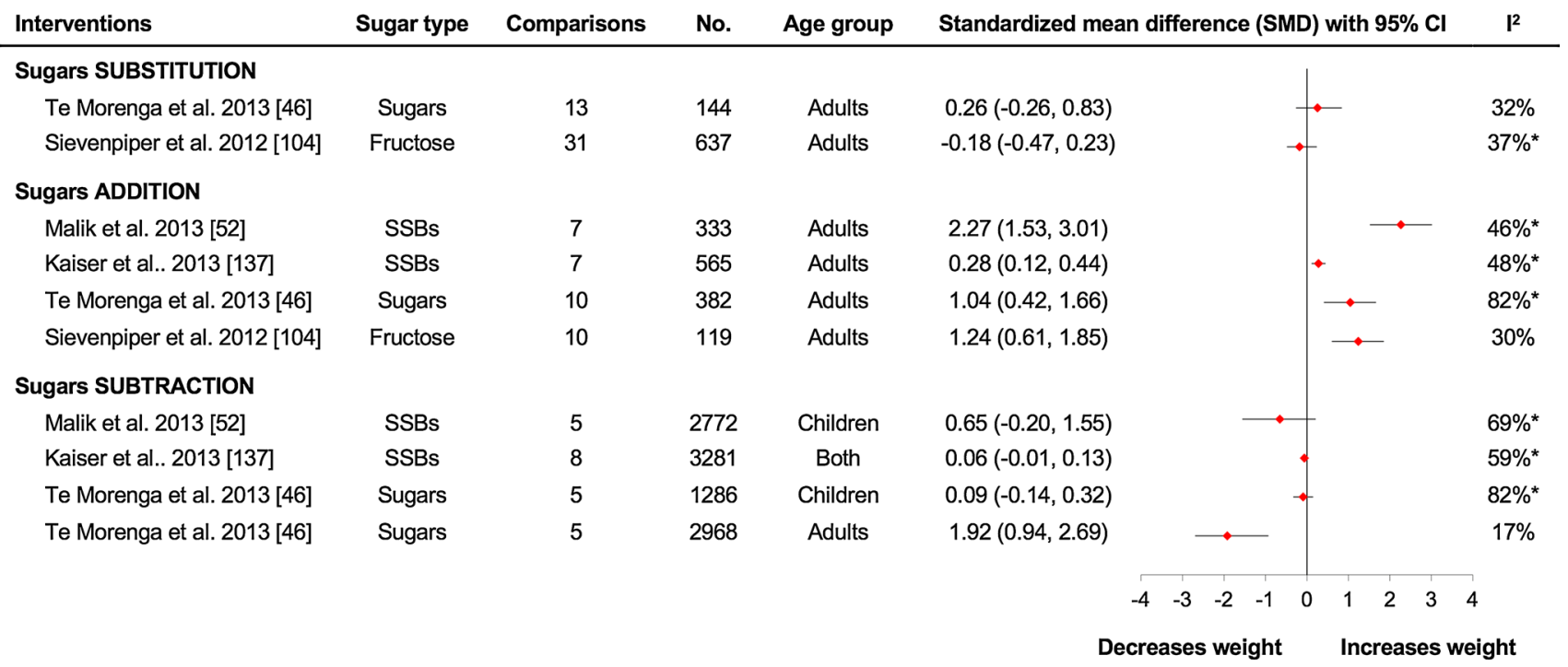

Fig. 6 Fructose-containing sugars and weight change in controlled dietary trials. Forest plots of summary estimates from recent metaanalyses of the effect of different fructose-containing sugars interventions on indices of body weight in controlled dietary trials involving children and adults. The meta-analyses were grouped broadly based on the interventions in question: isocaloric sugar substitution interventions, in which sugars were exchanged for other carbohydrate sources under energy-matched conditions; sugar supplementation interventions, in which sugars supplement background diets providing excess energy compared with the background diets alone without the excess energy; and sugar reduction interventions, in which excess from sugars is reduced in background diets compared with the background diets still containing the sugars. Indices of body weight included body weight in Sievenpiper et al. [107], Kaiser et al. [140] and Te Morenga et al. [49]. For isocaloric sugar substitution only; body fatness in Te Morenga et al. [49] for all other comparisons; and BMI $z$ scores in Malik et al. [55]. Summary estimates (diamonds) were derived from pooled trial-level data. To allow the summary estimates for each endpoint to be displayed on the same axis, mean differences (MDs) were transformed to standardized means differences (SMDs). Pseudo-95\% confidence intervals (CI) for each transformed SMD were derived directly from the original MD and $95 \%$ CI. Asterisks indicate significant interstudy heterogeneity as assessed by the Cochran $Q$ statistic and quantified by the $I^{2}$-statistic at a significance level of $P<.10$. SSBs sugar-sweetened beverages, No. total number of participants included in the meta-analysis of the controlled dietary trials 
sugars including high glycaemic index sugars like glucose and maltose. Two, it is possible that the type of analysis performed did not allow separation of the effect of fructose from calories, as almost 40 per cent of the studies in people who consumed ad libitum diets had no strict control of energy intake. Three, the isocaloric trials were not strictly isocaloric as the trials did not include adequate measures of compliance. Four, there was significant unexplained heterogeneity in the trials and imprecision of the summary pooled estimates of most endpoints. Conversely, our most recently concluded systematic review and meta-analysis of controlled trials found that fructose-containing sugars in isocaloric comparisons with other sources of macronutrients (mainly starch) had a beneficial effect on HbAlc levels and no effect on fasting glucose or insulin levels [132]. Therefore, with the above mixed signals, it is difficult to draw strong inferences about harm or benefit for fructose-containing sugars when isocalorically exchanged with other carbohydrates.

How does fructose-containing sugars fare against macronutrients other than carbohydrates, e.g. fat and protein? Most studies comparing fructose-containing sugars with fat and protein used SSBs as the form of dietary sugars. Looking at weight gain, no difference in body weight or total body fat was seen when SSBs were substituted isocalorically for milk in a trial in children for 16 months [135] and in adults for 6 months [136]. The adult trial showed that high SSB consumption (1 1/day providing $106 \mathrm{~g} /$ day in added sugars) increased liver and visceral fat composition, total cholesterol and triglycerides which was not seen in calorically equivalent intake of milk [136]; in fact, milk was beneficial in reducing blood pressure. It should be noted that the dose of added sugars consumed from SSBs in this trial was at more than twice the average US population intake (which is 1.3 servings or $429 \mathrm{ml} /$ day) [94]. Another 3-week trial in pre-diabetic adults of the substitution of SSBs with dairy milk also did not show any difference in weight [137]. Two studies under a negative energy balance comparing isocaloric substitutions found similar reductions in bodyweight for comparisons of sucrose versus protein or fat $[138,139]$. Thus, the overall picture from substitution trials indicates that fructose-containing sugars do not appear to behave differently from other sources of macronutrients in contributing to weight gain and that there is no clear evidence for cardiometabolic harms as results are not consistent across studies.

Compared to substitution trials, consistent signal of harm was seen in the addition trials. Four systematic reviews and meta-analyses found that supplementing the diet with excess energy from fructose-containing sugars resulted in significant weight gain when compared with the same diets alone without the excess energy (see Fig. 6). The first one was the WHO-commissioned systematic review and meta-analysis of ten RCTs involving 382 adults [49]. The next two systematic reviews and meta-analyses were based upon SSB beverages intake. The study by Kaiser et al. [140] included seven RCTs with 565 adults, and the study by Malik et al. [55] included seven RCTs in 292 adults. Both studies found that supplementing diet with fructose-containing sugars in form of SSBs, providing from 150 to $530 \mathrm{kcal}$ in excess calories over a period of 3 weeks-24 months, resulted in significant weight gain. Unsurprisingly, the weight gain achieved was proportional to the degree of excess calories added to the diet with some compensation [140]. In our own systematic review and meta-analysis of controlled trials, we found that fructosecontaining sugars supplementing diets with excess calories, when compared with same diets without the excess calories, showed an adverse effect on fasting insulin but not on $\mathrm{HbA1c}$ or fasting glucose levels [132].

In the pooled analyses of subtraction trials in which calories in the diet provided by fructose-containing sugars (as added sugars or SSBs) are removed and replaced with water or non-caloric beverages, results have not shown a consistent associated with weight loss [49, 55, 140]. An observed benefit on weight was seen only in adults in a pooled analysis of five trials comprising of 2968 participants [49], in a meta-analysis of seven trials involving 2637 participants when restricted to overweight/obese individuals [140] and in a meta-analysis of 15 trials with 1591 participants using low-calorie sweeteners [141]. However, such benefit was not seen in two systematic review and meta-analyses restricted to children $[49,55]$, though the study by Malik et al. [55] involving five trials with 1298 participants did show a potential benefit of subtraction trials when limited to overweight and obese children only. Interestingly, the interventions in the subtraction trials were more modest than those in the addition trials, meaning the caloric difference between intervention and control arm was less and more representative of real-world intakes. Such modest effects and also the inconsistency in the results might be explained by a compensatory effect, in which people will compensate for a decrease of energy from one source by increasing intake of other foods or exert less energy to maintain a neutral energy balance [142]. Therefore, substantial weight loss by reducing SSB intake and thus sugars might be difficult in free-living conditions [140]. This was demonstrated by the Choose Healthy Options Consciously Everyday (CHOICE) trial, where the weight loss from strategy of reducing calories from SSBs did not differ from general weight loss advice at 6 months [143].

Few randomized trials have assessed the effect of displacing calories from sugars using no- or low-calorie sweeteners or water on cardiometabolic risk factors. The systematic review and meta-analysis by WHO group [134] of 39 trials only identified one subtraction trial, which used 
ad libitum sugar-free diet as the control, and it did not show an effect on total cholesterol, HDL-C or triglyceride levels in 32 hypertriglyceridemic men [144]. Our own systematic review and meta-analysis of five studies in 591 participants did not show an effect of reducing calories from fructosecontaining sugars on $\mathrm{HbA} 1 \mathrm{c}$, fasting glucose or fasting insulin levels [132].

Ad libitum trials reflect real-world patterns to assess the effect of replacing fructose-containing sugars with other nutrients on weight gain and downstream cardiometabolic risk beyond the calories they provide. In these studies, fructose-containing sugars are freely replaced with other sources of energy in the diet without any requirement of a predetermined load nor a strict control of replacement or the background diet. We found very few studies with such design. The largest and the longest duration ad libitum trial was the CArbohydrate Ratio Management in European National Diets (CARMEN) study [145]. It compared ad libitum high-sugar diet ( 55\% energy carbohydrate, 29\% energy sugars), an ad libitum high complexcarbohydrate diet ( $\sim 51 \%$ energy carbohydrate, $19 \%$ energy sugars) and an ad libitum higher fat control diet ( $46 \%$ energy carbohydrate, $21 \%$ energy sugars) in 398 moderately obese adults over 6 months. The weight loss and reduction in body fat were no different between ad libitum high-fructose-containing sugars diet and ad libitum high complex-carbohydrate diet, although there was a tendency for greater weight loss on the ad libitum complex-carbohydrate diet ( -0.9 vs. $-1.8 \mathrm{~kg}$ ), possibly due to higher fibre and protein content. Another randomized study of 46 participants with metabolic syndrome following the same protocol over 6 months showed similar results [146]. In this study, those on the ad libitum high-fructose-containing sugars diet lost considerably more weight than those on the ad libitum higher fat control diet $(-0.28$ vs. $+1.03 \mathrm{~kg})$, although those on the high complex-carbohydrate diet lost the most weight $(-4.25 \mathrm{~kg})$. A third randomized trial in 20 normal-weight women followed over 2 weeks had a greater weight loss and lower plasma lipids in starch trial versus fat or sucrose arm [147]. Our own systematic review and meta-analysis of controlled trials showed no effect on $\mathrm{HbA1c}$, fasting glucose or fasting insulin levels irrespective of comparator [132]. In short, evidence suggests that, under free-living conditions, it is possible to lose weight following an ad libitum diet where fructose-containing sugars are replaced with complex-carbohydrate diets that are higher in protein and fibre, but there might not be any clear advantages if replaced with other sources of energy especially from fat. However, the effect on other cardiometabolic markers is not clear and more evidence is needed.

\section{Should we target sugars}

A lesson we can learn from the fat paradigm is that there can be unintended consequences of focusing singly on one nutrient. When saturated fat was deemed harmful, the industry responded by producing low-fat products, with no resultant appreciable calorie change, as in these products calories from fat were replaced with calories from other sources, e.g. starches and other sugars like maltodextrins [7]. The public perception changed as 'low-fat' products were deemed 'healthy', and a concomitant increase in availability on the supermarket shelf likely led to the overconsumption of such 'low-fat' products [148]. Not surprisingly, the expected reduction in cardiometabolic disease with the 'low-fat' food was not seen, and instead, we saw an unprecedented increase in incidence of overweight/obesity [149] and diabetes [150].

If a similar approach is taken by the industry who producing 'low-sugar' food products, a replay of the above scenario looks likely. Furthermore, the unique functional properties of fructose-containing sugars mean that their replacement is not as easy as it sounds. The functions provided in food products by sugars are related to their sensory (sweetness, taste and aroma, texture and appearance), physical (crystallization, viscosity, osmotic pressure, hygroscopicity, consistency/bulk, grain size and distribution), microbial (preservation and fermentation) and chemical (inversion and caramelization) properties [151]. Therefore, reducing or replacing sugar means one has to replace sugars with several ingredients in order to fulfil the above properties which, in many cases, may not result in calorie reduction [106]. Most commonly sugars are replaced with bulking agents, and most of these bulking agents also provide energy as most are carbohydratebased, e.g. isomaltulose, sugar alcohols, maltodextrins and starch hydrolysates, and some are fat based. Thus, the calorie reduction in 'low-sugar' products might be negligible or in some cases might even increase [106]. Another side effect of a drastic reduction in sugars is that even good sources of sugars might be targeted like whole grains. For example, the calories per serving are the same $(110 \mathrm{kcal} / 30 \mathrm{~g})$ in Frosted Flakes and Reduced Sugar Frosted Flakes despite the total sugar content being 11 and versus $8 \mathrm{~g}$, respectively. Despite appearing paradoxical, the replacement of sugars with refined corn starch means that glycaemic index of the flake product increases from 55 to 75 [152], and such an increase of GI at a whole diet level can potentially be associated with higher rates of diabetes [153]. Evidence from National Health and Nutrition Examination Survey (NHANES) 
data suggests that while at the population level in USA, consumption of added sugars has decreased in past two decades, there has been an increase in calories from other sources including other carbohydrates, protein and fatssuch that average daily calories have not reduced [154].

\section{Summary}

Despite the continuing concern regarding fructose's unique metabolic effects, which stems from low-quality ecological studies, animal models and select human studies, the highest level of evidence from systematic review and metaanalysis does not support a direct causal relationship with cardiometabolic disease. Using the totality of the highest quality evidence from controlled feeding trials, we demonstrate that fructose-containing sugars can lead to weight gain, increase in cardiometabolic risk factors and disease only if it provides the excess calories. When the calories are matched, fructose-containing sugars do not appear to cause weight gain compared to other forms of macronutrients including complex carbohydrates, fats and protein, and in low doses fructose might even show benefit. Prospective cohort studies, which provide the strongest observational evidence, have shown an association between fructose-containing sugars and cardiometabolic risk including weight gain, cardiovascular disease outcomes and diabetes only when restricted to SSBs and not for sugars from other sources. In fact, the harmful effect of SSBs is likely driven by a collinearity with an unhealthy lifestyle as SSB drinkers consume more calories, exercise less, smoke more and have a poor dietary pattern.

In summary, there is nothing unique about the sugar, fructose. It is harmful when in excess but potentially beneficial when taken in small amounts-providing evidence that it is the excess energy that is causing harm and not some unique metabolic effect. Still, the potential for overconsumption of sugars in form of sugary foods and drinks is substantial, and targeting added sugars as a source of excess calories appears to be a prudent strategy. However, sugar content should not be seen as the sole determinant of a healthy diet. There are many other factors in the diet—some providing excess calories while others provide beneficial nutrients. We should consider the whole diet for health benefits compared to just focusing on one nutrient. In this regard, improvements in dietary patterns appear to have the greatest influence on weight gain and cardiometabolic risk and represent the best opportunity for successful intervention.

Funding Aspects of this work were supported by the Canadian Diabetes Association, Canadian Institutes of Health Research Knowledge Synthesis Program (Funding Reference Number 102078) and Programmatic Grants in Food and Health through the Canada-wide Human Nutrition Trialists' Network (Funding Reference Number
129920). JLS was funded by a PSI Graham Farquharson Knowledge Translation Fellowship, Canadian Diabetes Association (CDA), Clinician Scientist Award, CIHR INMD/CNS New Investigator Partnership Prize and Banting and Best Diabetes Centre Sun Life Financial New Investigator Award. None of the sponsors had a role in any aspect of the present study, including design and conduct of the study; collection, management, analysis and interpretation of the data; and preparation, review, approval of the manuscript or decision to publish.

\section{Compliance with ethical standards}

Conflict of interest JLS has received research support from the Canadian Institutes of health Research (CIHR), Canadian Diabetes Association (CDA), PSI Foundation, Calorie Control Council, Banting and Best Diabetes Centre (BBDC), American Society for Nutrition (ASN), Dr. Pepper Snapple Group (investigator initiated, unrestricted donation), INC International Nut and Dried Fruit Council, and The Tate and Lyle Nutritional Research Fund at the University of Toronto. He has received travel reimbursement, speaker fees, and/or honoraria from the Canadian Diabetes Association (CDA), Canadian Nutrition Society (CNS), University of Alabama at Birmingham, Abbott Laboratories, Canadian Sugar Institute, Dr. Pepper Snapple Group, The Coca-Cola Company, Dairy Farmers of Canada, Nutrition Foundation of Italy (NFI), C3 Collaborating for Health, WhiteWave Foods, Rippe Lifestyle, mdBriefcase, Alberta Milk, FoodMinds LLC, Memac Ogilvy \& Mather LLC, PepsiCo, and Pulse Canada. He has ad hoc consulting arrangements with Winston \& Strawn LLP, Perkins Coie LLP, and Tate \& Lyle. $\mathrm{He}$ is a member of the European Fruit Juice Association Scientific Expert Panel. He is on the Clinical Practice Guidelines Expert Committees of the Canadian Diabetes Association (CDA), European Association for the study of Diabetes (EASD), and Canadian Cardiovascular Society (CCS), as well as an expert writing panel of the American Society for Nutrition (ASN). He serves as an unpaid scientific advisor for the Food, Nutrition, and Safety Program (FNSP) and the Technical Committee on Carbohydrates of the International Life Science Institute (ILSI) North America. $\mathrm{He}$ is a member of the International Carbohydrate Quality Consortium (ICQC), Executive Board Member of the Diabetes and Nutrition Study Group (DNSG) of the EASD, and Director of the Toronto 3D Knowledge Synthesis and Clinical Trials foundation. His wife is an employee of Unilever Canada. TAK declares no conflicts of interest.

Open Access This article is distributed under the terms of the Creative Commons Attribution 4.0 International License (http://creativecommons.org/licenses/by/4.0/), which permits unrestricted use, distribution, and reproduction in any medium, provided you give appropriate credit to the original author(s) and the source, provide a link to the Creative Commons license, and indicate if changes were made.

\section{References}

1. Malhotra A (2013) The dietary advice on added sugar needs emergency surgery. BMJ 346:f3199. doi:10.1136/bmj.f3199

2. Bray GA (2012) Fructose and risk of cardiometabolic disease. Curr Atheroscler Rep 14(6):570-578. doi:10.1007/ s11883-012-0276-6

3. Johnson RJ, Nakagawa T, Sanchez-Lozada LG, Shafiu M, Sundaram S, Le M, Ishimoto T, Sautin YY, Lanaspa MA (2013) Sugar, uric acid, and the etiology of diabetes and obesity. Diabetes 62(10):3307-3315. doi:10.2337/db12-1814

4. Lustig RH (2016) Response to "Metabolic improvement with fructose restriction: is it the fructose or the weight loss?". Obesity. doi:10.1002/oby. 21438 
5. World Health Organisation (2015) WHO calls on countries to reduce sugars intake among adults and children. http://who.int/ mediacentre/news/releases/2015/sugar-guideline/en/. Accessed 15 Sep 2015

6. Canadian Diabetes Association (2015) CDA's position on sugars. http://www.diabetes.ca/about-cda/publicpolicy-positionstatements/sugars. Accessed 9 Sep 2016

7. Willett W (1998) Dietary fat and obesity: an unconvincing relation. Am J Clin Nutr 68(6):1149-1150

8. Bray GA, Popkin BM (1998) Dietary fat intake does affect obesity! Am J Clin Nutr 68(6):1157-1173

9. Keys A et al (1970) Coronary heart disease in seven countries. Circulation 41(1):186-195

10. Yudkin J (1972) Pure, white and deadly: the problem of sugar. Davis-Poynter Limited

11. Watts G (2013) Sugar and the heart: old ideas revisited. BMJ 346:e7800. doi:10.1136/bmj.e7800

12. Bray GA, Nielsen SJ, Popkin BM (2004) Consumption of highfructose corn syrup in beverages may play a role in the epidemic of obesity. Am J Clin Nutr 79(4):537-543

13. Porta M, Greenland S, Hernán M, dos Santos SilvaI, Last JM (2014) A dictionary of epidemiology. Oxford University Press, Oxford

14. Grimes DA, Schulz KF (2002) Descriptive studies: what they can and cannot do. Lancet 359(9301):145-149. doi:10.1016/ S0140-6736(02)07373-7

15. The University of California (2009) Sugar: the bitter truth. Youtube

16. Lustig RH, Schmidt LA, Brindis CD (2012) Public health: the toxic truth about sugar. Nature 482(7383):27-29. doi:10.1038/482027a

17. Lustig RH (2013) Fructose: it's "alcohol without the buzz". Adv Nutr Int Rev J 4(2):226-235

18. Malhotra A (2013) Saturated fat is not the major issue. BMJ 347:f6340. doi:10.1136/bmj.f6340

19. DiNicolantonio JJ, O'Keefe JH, Lucan SC (2015) Added fructose. Mayo Clin Proc 90(3):372-381. doi:10.1016/j. mayocp.2014.12.019

20. Macgregor GA, Hashem KM (2014) Action on sugar-lessons from UK salt reduction programme. Lancet 383(9921):929931. doi:10.1016/S0140-6736(14)60200-2

21. Taubes G (2011) Is sugar toxic? The New York Times, $2011 / 4 / 13$

22. Lustig R (2013) Fat chance: the bitter truth about sugar. Fourth Estate

23. Gameau D (2015) That sugar film. http://www.imdb.com/title/ tt3892434/. Accessed 24 Oct 2016

24. Lustig RH (2016) Sickeningly sweet: does sugar cause type 2 diabetes? Yes. Can J Diabetes 40(4):282-286. doi:10.1016/j. jcjd.2016.01.004

25. Sievenpiper JL (2016) Sickeningly sweet: does sugar cause chronic disease? No. Can J Diabetes 40(4):287-295

26. Kearns CE, Schmidt LA, Glantz SA (2016) Sugar industry and coronary heart disease research: a historical analysis of internal industry documents. JAMA Intern Med 176(11):1680-1685. doi:10.1001/jamainternmed.2016.5394

27. Globe and Mail (2016) Sugar is the new tobacco. Here's why. http://www.theglobeandmail.com/life/health-and-fitness/healthadvisor/sugar-is-the-new-tobacco-hereswhy/article16571374/. Accessed 10 Aug 2016

28. Elliott SS, Keim NL, Stern JS, Teff K, Havel PJ (2002) Fructose, weight gain, and the insulin resistance syndrome. Am J Clin Nutr 76(5):911-922

29. Stanhope KL, Schwarz JM, Keim NL, Griffen SC, Bremer AA, Graham JL, Hatcher B, Cox CL, Dyachenko A, Zhang W, McGahan JP, Seibert A, Krauss RM, Chiu S, Schaefer EJ, Ai M, Otokozawa S, Nakajima K, Nakano T, Beysen C, Hellerstein
MK, Berglund L, Havel PJ (2009) Consuming fructose-sweetened, not glucose-sweetened, beverages increases visceral adiposity and lipids and decreases insulin sensitivity in overweight/ obese humans. J Clin Invest 119(5):1322-1334. doi:10.1172/ JCI37385

30. Johnson RJ, Perez-Pozo SE, Sautin YY, Manitius J, SanchezLozada LG, Feig DI, Shafiu M, Segal M, Glassock RJ, Shimada M, Roncal C, Nakagawa T (2009) Hypothesis: could excessive fructose intake and uric acid cause type 2 diabetes? Endocr Rev 30(1):96-116. doi:10.1210/er.2008-0033

31. Teff KL, Elliott SS, Tschöp M, Kieffer TJ, Rader D, Heiman M, Townsend RR, Keim NL, D'Alessio D, Havel PJ (2004) Dietary fructose reduces circulating insulin and leptin, attenuates postprandial suppression of ghrelin, and increases triglycerides in women. J Clin Endocrinol Metab 89(6):2963-2972

32. Page KA, Chan O, Arora J, Belfort-Deaguiar R, Dzuira J, Roehmholdt B, Cline GW, Naik S, Sinha R, Constable RT, Sherwin RS (2013) Effects of fructose vs glucose on regional cerebral blood flow in brain regions involved with appetite and reward pathways. JAMA 309(1):63-70. doi:10.1001/jama.2012.116975

33. Almiron-Roig E, Palla L, Guest K, Ricchiuti C, Vint N, Jebb SA, Drewnowski A (2013) Factors that determine energy compensation: a systematic review of preload studies. Nutr Rev 71(7):458-473. doi:10.1111/nure.12048

34. Sievenpiper JL, de Souza RJ, Kendall CWC, Jenkins DJA (2011) Is fructose a story of mice but not men? J Am Diet Assoc 111(2):219-220. doi:10.1016/j.jada.2010.12.001 (author reply 220-212)

35. Bray GA (2010) Fructose: pure, white, and deadly? Fructose, by any other name, is a health hazard. J Diabetes Sci Technol 4(4):1003-1007

36. van Buul VJ, Tappy L, Brouns FJPH (2014) Misconceptions about fructose-containing sugars and their role in the obesity epidemic. Nutr Res Rev 27(1):119-130. doi:10.1017/ S0954422414000067

37. Basu S, Yoffe P, Hills N, Lustig RH (2013) The relationship of sugar to population-level diabetes prevalence: an econometric analysis of repeated cross-sectional data. PLoS One 8(2):e57873. doi:10.1371/journal.pone.0057873

38. Gallaher DD (1992) Animal models in human nutrition research. Nutr Clin Pract 7(1):37-39

39. Tappy L, Lê K-A (2010) Metabolic effects of fructose and the worldwide increase in obesity. Physiol Rev 90(1):23-46. doi:10.1152/physrev.00019.2009

40. Sun SZ, Empie MW (2012) Fructose metabolism in humanswhat isotopic tracer studies tell us. Nutr Metab 9(1):89. doi:10.1186/1743-7075-9-89

41. Dietary Guidelines Advisory Committee (2015) 2015-2020 Dietary guidelines for americans. USDA and US Department of Health and Human Services, Washington, DC https://health. gov/dietaryguidelines/2015/. Accessed 24 Oct 2016

42. Scientific Advisory Committee on Nutrition (2015) Carbohydrates and Health report. https://www.gov.uk/government/publications/sacn-carbohydrates-and-health-report. Accessed 24 Oct 2016

43. Heart and Stroke Foundation of Canada (2014) Position statement on Sugar, heart disease and stroke. https://web.archive. org/web/20160827024321/http://www.heartandstroke.com/ site/c.ikIQLcMWJtE/b.9201361/k.47CB/Sugar_heart_disease_ and_stroke.htm. Accessed 27 Aug2016

44. Molander E, Virtanen S, Thorgeisdottir H, Aarum A, Mattisson I (2013) Nordic nutrition recommendations 2012 integrating nutrition and physical activity. Nordic Council of Ministers, Copenhagen

45. Woolf SH, Battista RN, Anderson GM, Logan AG, Wang E, Canadian Task Force on the Periodic Health Examination 
(1990) Assessing the clinical effectiveness of preventive maneuvers: analytic principles and systematic methods in reviewing evidence and developing clinical practice recommendations A report by the Canadian task force on the periodic health examination. J Clin Epidemiol 43(9):891-905. doi:10.1016/0895-4356(90)90073-X

46. US Preventive Services Task Force (2009) The guide to clinical preventive services 2009. Agency for Healthcare Research and Quality (US). https://www.ncbi.nlm.nih.gov/books/ NBK37637/. Accessed 24 Oct 2016

47. NICE (2006) Methods for the development of NICE public health guidance. NICE, London

48. Song JW, Chung KC (2010) Observational studies: cohort and case-control studies. Plast Reconstr Surg 126(6):2234

49. Te Morenga L, Mallard S, Mann J (2013) Dietary sugars and body weight: systematic review and meta-analyses of randomised controlled trials and cohort studies. BMJ 346:e7492. doi:10.1136/bmj.e7492

50. Janket S-J, Manson JE, Sesso H, Buring JE, Liu S (2003) A prospective study of sugar intake and risk of type 2 diabetes in women. Diabetes Care 26(4):1008-1015

51. Jayalath VH, Sievenpiper JL, de Souza RJ, Ha V, Mirrahimi A, Santaren ID, Blanco Mejia S, Di Buono M, Jenkins AL, Leiter LA, Wolever TMS, Beyene J, Kendall CWC, Jenkins DJA (2014) Total fructose intake and risk of hypertension: a systematic review and meta-analysis of prospective cohorts. J Am Coll Nutr 33(4):328-339. doi:10.1080/07315724.2014.916237

52. Liu S, Willett WC, Stampfer MJ, Hu FB, Franz M, Sampson L, Hennekens CH, Manson JE (2000) A prospective study of dietary glycemic load, carbohydrate intake, and risk of coronary heart disease in US women. Am J Clin Nutr 71(6):1455-1461

53. Jamnik J, Rehman S, Blanco Mejia S, Khan TA, Leiter LA, Wolever TMS, Kendall CWC, Jenkins DJA, Sievenpiper JL (2016) Fructose intake and risk of gout and hyperuricemia: a systematic review and meta-analysis of prospective cohort studies. BMJ Open 6(10):e013191. doi:10.1136/ bmjopen-2016-013191

54. Hu FB, Malik VS (2010) Sugar-sweetened beverages and risk of obesity and type 2 diabetes: epidemiologic evidence. Physiol Behav 100(1):47-54. doi:10.1016/j.physbeh.2010.01.036

55. Malik VS, Pan A, Willett WC, Hu FB (2013) Sugar-sweetened beverages and weight gain in children and adults: a systematic review and meta-analysis. Am J Clin Nutr 98(4):1084-1102. doi:10.3945/ajen.113.058362

56. Imamura F, O'Connor L, Ye Z, Mursu J, Hayashino Y, Bhupathiraju SN, Forouhi NG (2015) Consumption of sugar sweetened beverages, artificially sweetened beverages, and fruit juice and incidence of type 2 diabetes: systematic review, meta-analysis, and estimation of population attributable fraction. BMJ 351:h3576. doi:10.1136/bmj.h3576

57. Malik VS, Popkin BM, Bray GA, Després J-P, Willett WC, Hu FB (2010) Sugar-sweetened beverages and risk of metabolic syndrome and type 2 diabetes: a meta-analysis. Diabetes Care 33(11):2477-2483. doi:10.2337/dc10-1079

58. Jayalath VH, de Souza RJ, Ha V, Mirrahimi A, Blanco-Mejia S, Di Buono M, Jenkins AL, Leiter LA, Wolever TMS, Beyene J, Kendall CW, Jenkins DJ, Sievenpiper JL (2015) Sugarsweetened beverage consumption and incident hypertension: a systematic review and meta-analysis of prospective cohorts. Am J Clin Nutr. doi:10.3945/ajen.115.107243

59. de Koning L, Malik VS, Kellogg MD, Rimm EB, Willett WC, Hu FB (2012) Sweetened beverage consumption, incident coronary heart disease, and biomarkers of risk in men. Circulation 125(14):1735-1741. doi:10.1161/ CIRCULATIONAHA.111.067017
60. Huang C, Huang J, Tian Y, Yang X, Gu D (2014) Sugar sweetened beverages consumption and risk of coronary heart disease: a meta-analysis of prospective studies. Atherosclerosis 234(1):11-16. doi:10.1016/j.atherosclerosis.2014.01.037

61. Bernstein AM, de Koning L, Flint AJ, Rexrode KM, Willett WC (2012) Soda consumption and the risk of stroke in men and women. Am J Clin Nutr 95(5):1190-1199. doi:10.3945/ ajcn.111.030205

62. Choi HK, Willett W, Curhan G (2010) Fructose-rich beverages and risk of gout in women. JAMA 304(20):2270-2278. doi:10.1001/jama.2010.1638

63. de Souza R, Tawfik R, Sievenpiper J, Tsilas C (2014) No relation between total sugars intake and incident diabetes: a systematic review and meta-analysis of cohorts. In: Paper presented at the proceedings of the 32 nd international symposium on diabetes and nutrition, Reykjavik, Iceland, June 25-27

64. Xi B, Li S, Liu Z, Tian H, Yin X, Huai P, Tang W, Zhou D, Steffen LM (2014) Intake of fruit juice and incidence of type 2 diabetes: a systematic review and meta-analysis. PLoS One 9(3):e93471. doi:10.1371/journal.pone.0093471

65. Buijsse B, Boeing H, Drogan D, Schulze MB, Feskens EJ, Amiano P, Barricarte A, Clavel-Chapelon F, de Lauzon-Guillain B, Fagherazzi G, Fonseca-Nunes A, Franks PW, Huerta JM, Jakobsen MU, Kaaks R, Key TJ, Khaw KT, Masala G, Moskal A, Nilsson PM, Overvad K, Pala V, Panico S, Redondo ML, Ricceri F, Rolandsson O, Sánchez MJ, Sluijs I, Spijkerman AM, Tjonneland A, Tumino R, van der DL A, van der Schouw YT, Tumino R, Langenberg C, Sharp SJ, Forouhi NG, Riboli E, Wareham NJ, InterAct $C$ (2015) Consumption of fatty foods and incident type 2 diabetes in populations from eight European countries. Eur $\mathbf{J}$ Clin Nutr 69(4):455-461. doi:10.1038/ejcn.2014.249

66. Aune D, Norat T, Romundstad P, Vatten LJ (2013) Whole grain and refined grain consumption and the risk of type 2 diabetes: a systematic review and dose-response meta-analysis of cohort studies. Eur J Epidemiol 28(11):845-858. doi:10.1007/ s10654-013-9852-5

67. Aune D, Norat T, Romundstad P, Vatten LJ (2013) Dairy products and the risk of type 2 diabetes: a systematic review and dose-response meta-analysis of cohort studies. Am J Clin Nutr 98(4):1066-1083. doi:10.3945/ajen.113.059030

68. Sievenpiper JL, Tappy L, Brouns F (2015) Fructose as a driver of diabetes: an incomplete view of the evidence. Mayo Clin Proc 90(7):984-988. doi:10.1016/j.mayocp.2015.04.017

69. Li M, Fan Y, Zhang X, Hou W, Tang Z (2014) Fruit and vegetable intake and risk of type 2 diabetes mellitus: meta-analysis of prospective cohort studies. BMJ Open 4(11):e005497. doi:10.1136/bmjopen-2014-005497

70. Wang X, Ouyang Y, Liu J, Zhu M, Zhao G, Bao W, Hu FB (2014) Fruit and vegetable consumption and mortality from all causes, cardiovascular disease, and cancer: systematic review and dose-response meta-analysis of prospective cohort studies. BMJ 349:g4490. doi:10.1136/bmj.g4490

71. DiMeglio DP, Mattes RD (2000) Liquid versus solid carbohydrate: effects on food intake and body weight. Int J Obes Relat Metab Disord 24(6):794-800

72. Houchins JA, Burgess JR, Campbell WW, Daniel JR, Ferruzzi MG, McCabe GP, Mattes RD (2012) Beverage vs. solid fruits and vegetables: effects on energy intake and body weight. Obesity 20(9):1844-1850. doi:10.1038/oby.2011.192

73. Bertoia ML, Mukamal KJ, Cahill LE, Hou T, Ludwig DS, Mozaffarian D, Willett WC, Hu FB, Rimm EB (2015) Changes in intake of fruits and vegetables and weight change in United States men and women followed for up to 24 years: analysis from three prospective cohort studies. PLoS Med 12(9):e1001878. doi:10.1371/journal.pmed.1001878 
74. Madero M, Arriaga JC, Jalal D, Rivard C, McFann K, PérezMéndez O, Vázquez A, Ruiz A, Lanaspa MA, Jimenez CR, Johnson RJ, Lozada L-GS (2011) The effect of two energyrestricted diets, a low-fructose diet versus a moderate natural fructose diet, on weight loss and metabolic syndrome parameters: a randomized controlled trial. Metabolism 60(11):15511559. doi:10.1016/j.metabol.2011.04.001

75. Jenkins DJA, Srichaikul K, Kendall CWC, Sievenpiper JL, Abdulnour S, Mirrahimi A, Meneses C, Nishi S, He X, Lee S, So YT, Esfahani A, Mitchell S, Parker TL, Vidgen E, Josse RG, Leiter LA (2011) The relation of low glycaemic index fruit consumption to glycaemic control and risk factors for coronary heart disease in type 2 diabetes. Diabetologia 54(2):271-279. doi:10.1007/s00125-010-1927-1

76. Ranjit N, Evans MH, Byrd-Williams C, Evans AE, Hoelscher DM (2010) Dietary and activity correlates of sugar-sweetened beverage consumption among adolescents. Pediatrics 126(4):e754-e761. doi:10.1542/peds.2010-1229

77. Bleich SN, Wolfson JA (2015) U.S. adults and child snacking patterns among sugar-sweetened beverage drinkers and nondrinkers. Prev Med 72:8-14. doi:10.1016/j.ypmed.2015.01.003

78. Qi L (2009) Mendelian randomization in nutritional epidemiology. Nutr Rev 67(8):439-450. doi:10.1111/j.1753-4887.2009.00218.x.Mendelian

79. Vandenbroucke JP, von Elm E, Altman DG, Gøtzsche PC, Mulrow CD, Pocock SJ, Poole C, Schlesselman JJ, Egger M, Initiative $S$ (2007) Strengthening the reporting of observational studies in epidemiology (STROBE): explanation and elaboration. PLoS Med 4(10):e297. doi:10.1371/journal.pmed.0040297

80. Sievenpiper JL, de Souza RJ (2013) Are sugar-sweetened beverages the whole story? Am J Clin Nutr 98(2):261-263. doi:10.3945/ajen.113.067215

81. Fung TT, Rimm EB, Spiegelman D, Rifai N, Tofler GH, Willett WC, Hu FB (2001) Association between dietary patterns and plasma biomarkers of obesity and cardiovascular disease risk. Am J Clin Nutr 73(1):61-67

82. Malik VS, Schulze MB, Hu FB (2006) Intake of sugar-sweetened beverages and weight gain: a systematic review. Am J Clin Nutr 84(2):274-288

83. Schulze MB, Fung TT, Manson JE, Willett WC, Hu FB (2006) Dietary patterns and changes in body weight in women. Obesity 14(8):1444-1453. doi:10.1038/oby.2006.164

84. Malik VS, Willett WC, Hu FB (2009) Sugar-sweetened beverages and BMI in children and adolescents: reanalyses of a meta-analysis. Am J Clin Nutr 89(1):438-439. doi:10.3945/ ajcn.2008.26980 (author reply 439-440)

85. Forshee RA, Anderson PA, Storey ML (2008) Sugar-sweetened beverages and body mass index in children and adolescents: a meta-analysis. Am J Clin Nutr 87(6):1662-1671

86. Schulze MB, Hoffmann K, Manson JE, Willett WC, Meigs JB, Weikert C, Heidemann C, Colditz GA, Hu FB (2005) Dietary pattern, inflammation, and incidence of type 2 diabetes in women. Am J Clin Nutr 82(3):675-684 (quiz 675-714)

87. van Dam RM, Rimm EB, Willett WC, Stampfer MJ, Hu FB (2002) Dietary patterns and risk for type 2 diabetes mellitus in U.S. men. Ann Intern Med 136(3):201-209

88. Fung TT, Schulze M, Manson JE, Willett WC, Hu FB (2004) Dietary patterns, meat intake, and the risk of type 2 diabetes in women. Arch Intern Med 164(20):2235-2240. doi:10.1001/ archinte.164.20.2235

89. Montonen J, Knekt P, Harkanen T, Jarvinen R, Heliovaara M, Aromaa A, Reunanen A (2005) Dietary patterns and the incidence of type 2 diabetes. Am J Epidemiol 161(3):219-227. doi:10.1093/aje/kwi039

90. Fung TT, Willett WC, Stampfer MJ, Manson JE, Hu FB (2001) Dietary patterns and the risk of coronary heart disease in women. Arch Intern Med 161(15):1857-1862
91. Cohen L, Curhan G, Forman J (2012) Association of sweetened beverage intake with incident hypertension. J Gen Intern Med 27(9):1127-1134. doi:10.1007/s11606-012-2069-6

92. Singh GM, Micha R, Khatibzadeh S, Shi P, Lim S, Andrews KG, Engell RE, Ezzati M, Mozaffarian D, Global Burden of Diseases Nutrition and Chronic Diseases Expert Group (2015) Global, regional, and national consumption of sugar-sweetened beverages, fruit juices, and milk: a systematic assessment of beverage intake in 187 countries. PLoS One 10(8):e0124845. doi:10.1371/journal.pone.0124845

93. Lim SS, Vos T, Flaxman AD, Danaei G, Shibuya K, AdairRohani H, Amann M, Anderson HR, Andrews KG, Aryee M, Atkinson C, Bacchus LJ, Bahalim AN, Balakrishnan K, Balmes J, Barker-Collo S, Baxter A, Bell ML, Blore JD, Blyth F, Bonner C, Borges G, Bourne R, Boussinesq M, Brauer M, Brooks P, Bruce NG, Brunekreef B, Bryan-Hancock C, Bucello C, Buchbinder R, Bull F, Burnett RT, Byers TE, Calabria B, Carapetis J, Carnahan E, Chafe Z, Charlson F, Chen H, Chen JS, Cheng AT-A, Child JC, Cohen A, Colson KE, Cowie BC, Darby S, Darling S, Davis A, Degenhardt L, Dentener F, Des Jarlais DC, Devries K, Dherani M, Ding EL, Dorsey ER, Driscoll T, Edmond K, Ali SE, Engell RE, Erwin PJ, Fahimi S, Falder G, Farzadfar F, Ferrari A, Finucane MM, Flaxman S, Fowkes FGR, Freedman G, Freeman MK, Gakidou E, Ghosh S, Giovannucci E, Gmel G, Graham K, Grainger R, Grant B, Gunnell D, Gutierrez HR, Hall W, Hoek HW, Hogan A, Hosgood HD 3rd, Hoy D, Hu H, Hubbell BJ, Hutchings SJ, Ibeanusi SE, Jacklyn GL, Jasrasaria R, Jonas JB, Kan H, Kanis JA, Kassebaum N, Kawakami N, Khang Y-H, Khatibzadeh S, Khoo J-P, Kok C, Laden F, Lalloo R, Lan Q, Lathlean T, Leasher JL, Leigh J, Li Y, Lin JK, Lipshultz SE, London S, Lozano R, Lu Y, Mak J, Malekzadeh R, Mallinger L, Marcenes W, March L, Marks R, Martin R, McGale P, McGrath J, Mehta S, Mensah GA, Merriman TR, Micha R, Michaud C, Mishra V, Mohd Hanafiah K, Mokdad AA, Morawska L, Mozaffarian D, Murphy T, Naghavi M, Neal B, Nelson PK, Nolla JM, Norman R, Olives C, Omer SB, Orchard J, Osborne R, Ostro B, Page A, Pandey KD, Parry CDH, Passmore E, Patra J, Pearce N, Pelizzari PM, Petzold M, Phillips MR, Pope D, Pope CA III, Powles J, Rao M, Razavi H, Rehfuess EA, Rehm JT, Ritz B, Rivara FP, Roberts T, Robinson C, Rodriguez-Portales JA, Romieu I, Room R, Rosenfeld LC, Roy A, Rushton L, Salomon JA, Sampson U, Sanchez-Riera L, Sanman E, Sapkota A, Seedat S, Shi P, Shield K, Shivakoti R, Singh GM, Sleet DA, Smith E, Smith KR, Stapelberg NJC, Steenland K, Stöckl H, Stovner LJ, Straif K, Straney L, Thurston GD, Tran JH, Van Dingenen R, van Donkelaar A, Veerman JL, Vijayakumar L, Weintraub R, Weissman MM, White RA, Whiteford H, Wiersma ST, Wilkinson JD, Williams HC, Williams W, Wilson N, Woolf AD, Yip P, Zielinski JM, Lopez AD, Murray CJL, Ezzati M, AlMazroa MA, Memish ZA (2012) A comparative risk assessment of burden of disease and injury attributable to 67 risk factors and risk factor clusters in 21 regions, 1990-2010: a systematic analysis for the Global Burden of Disease Study 2010. Lancet 380(9859):2224-2260. doi:10.1016/S0140-6736(12)61766-8

94. Singh GM, Micha R, Khatibzadeh S, Lim S, Ezzati M, Mozaffarian D, Global Burden of Diseases Nutrition and Chronic Diseases Expert Group (2015) Estimated global, regional, and national disease burdens related to sugar-sweetened beverage consumption in 2010. Circulation 132(8):639-666. doi:10.1161/CIRCULATIONAHA.114.010636

95. Xi B, Huang Y, Reilly KH, Li S, Zheng R, Barrio-Lopez MT, Martinez-Gonzalez MA, Zhou D (2015) Sugar-sweetened beverages and risk of hypertension and CVD: a dose-response meta-analysis. $\mathrm{Br} \quad \mathrm{J}$ Nutr 113(5):709-717. doi:10.1017/ S0007114514004383 
96. Pan A, Sun Q, Bernstein AM, Schulze MB, Manson JE, Willett WC, Hu FB (2011) Red meat consumption and risk of type 2 diabetes: 3 cohorts of US adults and an updated meta-analysis. Am J Clin Nutr 94(4):1088-1096. doi:10.3945/ajen.111.018978

97. Micha R, Michas G, Mozaffarian D (2012) Unprocessed red and processed meats and risk of coronary artery disease and type 2 diabetes - an updated review of the evidence. Curr Atheroscler Rep 14(6):515-524. doi:10.1007/s11883-012-0282-8

98. Halton TL, Willett WC, Liu S, Manson JE, Stampfer MJ, Hu FB (2006) Potato and french fry consumption and risk of type 2 diabetes in women. Am J Clin Nutr 83(2):284-290

99. Bhupathiraju SN, Tobias DK, Malik VS, Pan A, Hruby A, Manson JE, Willett WC, Hu FB (2014) Glycemic index, glycemic load, and risk of type 2 diabetes: results from 3 large US cohorts and an updated meta-analysis. Am J Clin Nutr 100(1):218-232. doi:10.3945/ajen.113.079533

100. Cahill LE, Pan A, Chiuve SE, Sun Q, Willett WC, Hu FB, Rimm EB (2014) Fried-food consumption and risk of type 2 diabetes and coronary artery disease: a prospective study in 2 cohorts of US women and men. Am J Clin Nutr 100(2):667675. doi:10.3945/ajen.114.084129

101. Hu FB, Manson JE, Stampfer MJ, Colditz G, Liu S, Solomon CG, Willett WC (2001) Diet, lifestyle, and the risk of type 2 diabetes mellitus in women. N Engl J Med 345(11):790-797. doi:10.1056/NEJMoa010492

102. Thun MJ, Carter BD, Feskanich D, Freedman ND, Prentice R, Lopez AD, Hartge P, Gapstur SM (2013) 50-year trends in smoking-related mortality in the United States. N Engl J Med 368(4):351-364

103. Le Bodo Y, Paquette MC, Vallieres M, Almeras N (2015) Is sugar the new tobacco? Insights from laboratory studies, consumer surveys and public health. Curr Obes Rep 4(1):111-121. doi:10.1007/s13679-015-0141-3

104. Sugar is now enemy number one in the western diet|Aseem MalhotralOpinion/The Guardian. https://www.theguardian.com/ commentisfree/2014/jan/11/sugar-is-enemy-number-one-now. Accessed 11 Sep 2016

105. Mozaffarian D, Hao T, Rimm EB, Willett WC, Hu FB (2011) Changes in diet and lifestyle and long-term weight gain in women and men. N Engl J Med 364(25):2392-2404. doi:10.1056/NEJMoa1014296

106. Goldfein KR, Slavin JL (2015) Why sugar is added to food: food science 101. Compr Rev Food Sci Food Saf 14(5):644656. doi:10.1111/1541-4337.12151

107. Sievenpiper JL, de Souza RJ, Mirrahimi A, Yu ME, Carleton AJ, Beyene J, Chiavaroli L, Di Buono M, Jenkins AL, Leiter LA, Wolever TM, Kendall CW, Jenkins DJ (2012) Effect of fructose on body weight in controlled feeding trials: a systematic review and meta-analysis. Ann Intern Med 156(4):291-304. doi:10.7326/0003-4819-156-4-201202210-00007

108. Chiavaroli L, de Souza RJ, Ha V, Cozma AI, Mirrahimi A, Wang DD, Yu M, Carleton AJ, Di Buono M, Jenkins AL, Leiter LA, Wolever TMS, Beyene J, Kendall CWC, Jenkins DJA, Sievenpiper JL (2015) Effect of fructose on established lipid targets: a systematic review and meta-analysis of controlled feeding trials. J Am Heart Assoc 4(9):e001700. doi:10.1161/ JAHA.114.001700

109. Sievenpiper JL, Carleton AJ, Chatha S, Jiang HY, de Souza RJ, Beyene J, Kendall CW, Jenkins DJ (2009) Heterogeneous effects of fructose on blood lipids in individuals with type 2 diabetes: systematic review and meta-analysis of experimental trials in humans. Diabetes Care 32(10):1930-1937. doi:10.2337/dc09-0619

110. Ha V, Sievenpiper JL, de Souza RJ, Chiavaroli L, Wang DD, Cozma AI, Mirrahimi A, Yu ME, Carleton AJ, Dibuono M, Jenkins AL, Leiter LA, Wolever TMS, Beyene J, Kendall CWC, Jenkins DJA (2012) Effect of fructose on blood pressure: a systematic review and meta-analysis of controlled feeding trials. Hypertension 59(4):787-795. doi:10.1161/ HYPERTENSIONAHA.111.182311

111. Wang DD, Sievenpiper JL, de Souza RJ, Chiavaroli L, Ha V, Cozma AI, Mirrahimi A, Yu ME, Carleton AJ, Di Buono M, Jenkins AL, Leiter LA, Wolever TMS, Beyene J, Kendall CWC, Jenkins DJA (2012) The effects of fructose intake on serum uric acid vary among controlled dietary trials. J Nutr 142(5):916923. doi:10.3945/jn.111.151951

112. Cozma AI, Sievenpiper JL, de Souza RJ, Chiavaroli L, Ha V, Wang DD, Mirrahimi A, Yu ME, Carleton AJ, Di Buono M, Jenkins AL, Leiter LA, Wolever TMS, Beyene J, Kendall CWC, Jenkins DJA (2012) Effect of fructose on glycemic control in diabetes: a systematic review and meta-analysis of controlled feeding trials. Diabetes Care 35(7):1611-1620. doi:10.2337/dc12-0073

113. Sievenpiper JL, Chiavaroli L, de Souza RJ, Mirrahimi A, Cozma AI, Ha V, Wang DD, Yu ME, Carleton AJ, Beyene J, Di Buono M, Jenkins AL, Leiter LA, Wolever TMS, Kendall CWC, Jenkins DJA (2012) 'Catalytic' doses of fructose may benefit glycaemic control without harming cardiometabolic risk factors: a small meta-analysis of randomised controlled feeding trials. $\mathrm{Br}$ J Nutr 108(3):418-423. doi:10.1017/S000711451200013X

114. David Wang D, Sievenpiper JL, de Souza RJ, Cozma AI, Chiavaroli L, Ha V, Mirrahimi A, Carleton AJ, Di Buono M, Jenkins AL, Leiter LA, Wolever TMS, Beyene J, Kendall CWC, Jenkins DJA (2014) Effect of fructose on postprandial triglycerides: a systematic review and meta-analysis of controlled feeding trials. Atherosclerosis 232(1):125-133. doi:10.1016/j. atherosclerosis.2013.10.019

115. Chiu S, Sievenpiper JL, de Souza RJ, Cozma AI, Mirrahimi A, Carleton AJ, Ha V, Di Buono M, Jenkins AL, Leiter LA, Wolever TMS, Don-Wauchope AC, Beyene J, Kendall CWC, Jenkins DJA (2014) Effect of fructose on markers of nonalcoholic fatty liver disease (NAFLD): a systematic review and meta-analysis of controlled feeding trials. Eur J Clin Nutr 68(4):416-423. doi:10.1038/ejen.2014.8

116. Harper W, Clement M, Goldenberg R, Hanna A, Main A, Retnakaran R, Sherifali D, Woo V, Yale JF, Cheng AY (2015) Policies, guidelines and consensus statements: pharmacologic management of type 2 diabetes-2015 interim update. Can J Diabetes 39(4):250-252. doi:10.1016/j.jcjd.2015.05.009

117. Food and Drug Administration (2008) Guidance for industry diabetes mellitus: developing drugs and therapeutic biologics for treatment and prevention. http://www.fda.gov/downloads/ Drugs/.../Guidances/ucm071624.pdf. Accessed 24 Oct 2016

118. Livesey G, Taylor R (2008) Fructose consumption and consequences for glycation, plasma triacylglycerol, and body weight: meta-analyses and meta-regression models of intervention studies. Am J Clin Nutr 88(5):1419-1437

119. Sievenpiper JL, de Souza RJ, Cozma AI, Chiavaroli L, Ha V, Mirrahimi A (2014) Fructose vs. glucose and metabolism: do the metabolic differences matter? Curr Opin Lipidol 25(1):819. doi:10.1097/MOL.0000000000000042

120. Egli L, Lecoultre V, Theytaz F, Campos V, Hodson L, Schneiter P, Mittendorfer B, Patterson BW, Fielding BA, Gerber PA, Giusti V, Berneis K, Tappy L (2013) Exercise prevents fructoseinduced hypertriglyceridemia in healthy young subjects. Diabetes 62(7):2259-2265. doi:10.2337/db12-1651

121. Arrigoni E, Kast C, Walther B (2015) Effects of Dietary Sugars from Natural Sources on Health Outcomes. In: Goran M, Tappy L, Lê KA (eds) Dietary sugars and health. CRC Press Taylor Francis

122. Rippe JM (2014) Fructose, high fructose corn syrup, sucrose and health. Springer, Berlin

123. Hawkins M, Gabriely I, Wozniak R, Vilcu C, Shamoon H, Rossetti L (2002) Fructose improves the ability of hyperglycemia 
per se to regulate glucose production in type 2 diabetes. Diabetes 51(3):606-614

124. Vandercammen A, Detheux M, Van Schaftingen E (1992) Binding of sorbitol 6-phosphate and of fructose 1-phosphate to the regulatory protein of liver glucokinase. Biochem $\mathrm{J}$ 286(1):253-256

125. Detheux M, Vandercammen A, Schaftingen E (1991) Effectors of the regulatory protein acting on liver glucokinase: a kinetic investigation. Eur J Biochem 200(2):553-561

126. Van Schaftingen E, Detheux M, Veiga da Cunha M (1994) Short-term control of glucokinase activity: role of a regulatory protein. FASEB J 8(6):414-419

127. Agius L, Peak M (1993) Intracellular binding of glucokinase in hepatocytes and translocation by glucose, fructose and insulin. Biochem J 296(Pt 3):785-796

128. Petersen KF, Laurent D, Yu C, Cline GW, Shulman GI (2001) Stimulating effects of low-dose fructose on insulin-stimulated hepatic glycogen synthesis in humans. Diabetes 50(6):1263-1268

129. Heacock PM, Hertzler SR, Wolf BW (2002) Fructose prefeeding reduces the glycemic response to a high-glycemic index, starchy food in humans. J Nutr 132(9):2601-2604

130. Moore MC, Cherrington AD, Mann SL, Davis SN (2000) Acute fructose administration decreases the glycemic response to an oral glucose tolerance test in normal adults. J Clin Endocrinol Metab 85(12):4515-4519. doi:10.1210/jcem.85.12.7053

131. Moore MC, Davis SN, Mann SL, Cherrington AD (2001) Acute fructose administration improves oral glucose tolerance in adults with type 2 diabetes. Diabetes Care 24(11):1882-1887

132. Choo VL, Ha V, Blanco Mejia S, J S (2015) HFCS and sucrose on cardiometabolic risk: a series of systematic reviews and meta-analyses of controlled trials. In: Proceedings of the 2015 IDF word diabetes congress, Vancouver, BC, Canada, November 30-December 4

133. Egli L, Lecoultre V, Cros J, Rosset R, Marques A-S, Schneiter P, Hodson L, Gabert L, Laville M, Tappy L (2016) Exercise performed immediately after fructose ingestion enhances fructose oxidation and suppresses fructose storage. Am J Clin Nutr 103(2):348-355. doi:10.3945/ajcn.115.116988

134. Te Morenga LA, Howatson AJ, Jones RM, Mann J (2014) Dietary sugars and cardiometabolic risk: systematic review and meta-analyses of randomized controlled trials of the effects on blood pressure and lipids. Am J Clin Nutr 100(1):65-79. doi:10.3945/ajen.113.081521

135. Albala C, Ebbeling CB, Cifuentes M, Lera L, Bustos N, Ludwig DS (2008) Effects of replacing the habitual consumption of sugar-sweetened beverages with milk in Chilean children. Am J Clin Nutr 88(3):605-611

136. Maersk M, Belza A, Stødkilde-Jørgensen H, Ringgaard S, Chabanova E, Thomsen H, Pedersen SB, Astrup A, Richelsen B (2012) Sucrose-sweetened beverages increase fat storage in the liver, muscle, and visceral fat depot: a 6-mo randomized intervention study. Am J Clin Nutr 95(2):283-289

137. Maki K, Nieman K, Schild A, Kaden V, Lawless A, Kelley K, Rains T (2014) Effects of dairy vs. sugar-sweetened products on insulin sensitivity, pancreatic $\beta$-cell function and plasma lipids in men and women at risk for type 2 diabetes mellitus (117.3). FASEB J 28(1 Suppl.). http://www.fasebj.org/content/28/1_Supplement/117.3.abstract.

138. Hendler RG, Walesky M, Sherwin RS (1986) Sucrose substitution in prevention and reversal of the fall in metabolic rate accompanying hypocaloric diets. Am J Med 81(2):280-284

139. Hendler R, Bonde AA (1990) Effects of sucrose on resting metabolic rate, nitrogen balance, leucine turnover and oxidation during weight loss with low calorie diets. Int $\mathrm{J}$ Obes 14(11):927-938
140. Kaiser KA, Shikany JM, Keating KD, Allison DB (2013) Will reducing sugar-sweetened beverage consumption reduce obesity? Evidence supporting conjecture is strong, but evidence when testing effect is weak. Obes Rev 14(8):620-633. doi:10.1111/obr.12048

141. Miller PE, Perez V (2014) Low-calorie sweeteners and body weight and composition: a meta-analysis of randomized controlled trials and prospective cohort studies. Am J Clin Nutr 100(3):765-777

142. Reid M, Hammersley R, Duffy M (2010) Effects of sucrose drinks on macronutrient intake, body weight, and mood state in overweight women over 4 weeks. Appetite 55(1):130-136. doi:10.1016/j.appet.2010.05.001

143. Tate DF, Turner-McGrievy G, Lyons E, Stevens J, Erickson K, Polzien K, Diamond M, Wang X, Popkin B (2012) Replacing caloric beverages with water or diet beverages for weight loss in adults: main results of the choose healthy options consciously everyday (CHOICE) randomized clinical trial. Am J Clin Nutr 95(3):555-563. doi:10.3945/ajcn.111.026278

144. Smith JB, Niven BE, Mann JI (1996) The effect of reduced extrinsic sucrose intake on plasma triglyceride levels. Eur J Clin Nutr 50(8):498-504

145. Saris WH, Astrup A, Prentice AM, Zunft HJ, Formiguera X, Verboeket-van de Venne W, Raben A, Poppitt SD, Seppelt B, Johnston S et al (2000) Randomized controlled trial of changes in dietary carbohydrate/fat ratio and simple vs complex carbohydrates on body weight and blood lipids: the CARMEN study. Int J Obes 24(10):1310-1318

146. Poppitt SD, Keogh GF, Prentice AM, Williams DEM, Sonnemans HMW, Valk EEJ, Robinson E, Wareham NJ (2002) Longterm effects of ad libitum low-fat, high-carbohydrate diets on body weight and serum lipids in overweight subjects with metabolic syndrome. Am J Clin Nutr 75(1):11-20

147. Marckmann P, Raben A, Astrup A (2000) Ad libitum intake of low-fat diets rich in either starchy foods or sucrose: effects on blood lipids, factor VII coagulant activity, and fibrinogen. Metabolism 49(6):731-735

148. Suher J, Raghunathan R, Hoyer WD (2016) Eating healthy or feeling empty? How the "healthy = less filling" intuition influences satiety. J Assoc Consum Res 1(1):26-40

149. Ng M, Fleming T, Robinson M, Thomson B, Graetz N, Margono C, Mullany EC, Biryukov S, Abbafati C, Abera SF (2014) Global, regional, and national prevalence of overweight and obesity in children and adults during 1980-2013: a systematic analysis for the Global Burden of Disease Study 2013. Lancet 384(9945):766-781

150. Guariguata L, Whiting D, Hambleton I, Beagley J, Linnenkamp U, Shaw J (2014) Global estimates of diabetes prevalence for 2013 and projections for 2035. Diabetes Res Clin Pract 103(2):137-149

151. Davis EA (1995) Functionality of sugars: physicochemical interactions in foods. Am J Clin Nutr 62(1 Suppl.):170S-177S

152. Atkinson FS, Foster-Powell K, Brand-Miller JC (2008) International tables of glycemic index and glycemic load values: 2008 . Diabetes Care 31(12):2281-2283. doi:10.2337/dc08-1239

153. Greenwood DC, Threapleton DE, Evans CE, Cleghorn CL, Nykjaer C, Woodhead C, Burley VJ (2013) Glycemic index, glycemic load, carbohydrates, and type 2 diabetes: systematic review and dose-response meta-analysis of prospective studies. Diabetes Care 36(12):4166-4171. doi:10.2337/dc13-0325

154. Welsh JA, Sharma AJ, Grellinger L, Vos MB (2011) Consumption of added sugars is decreasing in the United States. Am J Clin Nutr 94(3):726-734. doi:10.3945/ajen.111.018366 